\title{
Mitochondria mediate cell membrane repair and contribute to Duchenne muscular dystrophy
}

\author{
Maria C Vila ${ }^{1,2,6}$, Sree Rayavarapu ${ }^{1,6,7}$, Marshall W Hogarth ${ }^{1}$, Jack H Van der Meulen ${ }^{1}$, Adam Horn ${ }^{1,2}$, Aurelia Defour ${ }^{1,8}$, Shin'ichi Takeda ${ }^{3}$, \\ Kristy J Brown ${ }^{1,4,5}$, Yetrib Hathout ${ }^{1,4,5}$, Kanneboyina Nagaraju ${ }^{1,4,5}$ and Jyoti K Jaiswal ${ }^{*, 1,4,5}$
}

Dystrophin deficiency is the genetic basis for Duchenne muscular dystrophy (DMD), but the cellular basis of progressive myofiber death in DMD is not fully understood. Using two dystrophin-deficient $m d x$ mouse models, we find that the mitochondrial dysfunction is among the earliest cellular deficits of $m d x$ muscles. Mitochondria in dystrophic myofibers also respond poorly to sarcolemmal injury. These mitochondrial deficits reduce the ability of dystrophic muscle cell membranes to repair and are associated with a compensatory increase in dysferlin-mediated membrane repair proteins. Dysferlin deficit in $m d x$ mice further compromises myofiber cell membrane repair and enhances the muscle pathology at an asymptomatic age for dysferlin-deficient mice. Restoring partial dystrophin expression by exon skipping improves mitochondrial function and offers potential to improve myofiber repair. These findings identify that mitochondrial deficit in muscular dystrophy compromises the repair of injured myofibers and show that this repair mechanism is distinct from and complimentary to the dysferlin-mediated repair of injured myofibers.

Cell Death and Differentiation (2017) 24, 330-342; doi:10.1038/cdd.2016.127; published online 11 November 2016

Duchenne muscular dystrophy (DMD) and its milder allelic form Becker muscular dystrophy result from mutations in the dystrophin gene. ${ }^{1}$ Dystrophin protein localizes at the cytoplasmic face of the muscle plasma membrane (sarcolemma). The C-terminus of dystrophin binds the dystrophin-associated protein complex (DAPC), which spans the sarcolemmal membrane and binds the extracellular matrix. ${ }^{2}$ The $\mathrm{N}$-terminus of dystrophin interacts with the actin cytoskeleton, anchoring the extracellular matrix to the actin cytoskeleton. ${ }^{2}$ This dystrophin-mediated link between the extracellular matrix and the intracellular cytoskeleton is essential for the stability of the sarcolemma. ${ }^{3}$ Lack of dystrophin disrupts the DAPC, reduces the sarcolemmal stiffness, and increases myofiber susceptibility to damage by physical stresses. ${ }^{3-7}$ This leads to increased myofiber death and triggers chronic inflammation, weakness, and degeneration of the muscle.,8-10 The damaged myofibers that undergo necrosis regenerate by muscle stem cells. ${ }^{11}$ But the mechanism by which DMD myofibers repair the damage to their sarcolemma and avoid necrotic death has not been investigated. DMD patient muscles show increased expression of the sarcolemmal repair protein dysferlin, and lack of dysferlin in adult $m d x$ mice (model for DMD) worsens the disease. ${ }^{12,13}$ Drugs that stabilize or improve sarcolemmal repair improve cardiac and skeletal muscle function in animal models of DMD. ${ }^{14-17}$ Thus stabilizing the sarcolemma and repairing damaged sarcolemma are viable approaches to reduce necrosis of dystrophin-deficient myofibers.

Calcium entry via sarcolemmal tears and/or activation of calcium leak channels by sarcolemmal stretching causes calcium overload in dystrophic muscle..$^{9,18-20}$ Although repair of sarcolemmal tears is a calcium-dependent process, calcium overload causes mitochondrial swelling, mitochondrial reactive oxygen species production, and mitochondrial permeability transition pore opening in dystrophin-deficient muscle. ${ }^{10,21-25}$ Reducing sarcoplasmic and organellar calcium overload in dystrophin-deficient and associated muscular dystrophies reduces disease pathology. ${ }^{23,25-27}$ However, the mechanism for repairing sarcolemmal damage in dystrophin-deficient myofibers has not been studied. We recently identified that active mitochondria are required for the repair of sarcolemmal injury in healthy myofibers. ${ }^{28}$ By quantitative analysis of the muscle proteome in $m d x$ mice, we found that proteins facilitating mitochondrial function, calcium homeostasis, and sarcolemmal stability are significantly altered at disease onset in $m d x$ mice. ${ }^{29}$ We hypothesize that

${ }^{1}$ Center for Genetic Medicine Research, Children's National Health System, 111 Michigan Avenue NW, Washington, DC 20010, USA; ${ }^{2}$ Institute for Biomedical Sciences, The George Washington University, 2300 Eye Street, N.W., Ross 605, Washington, DC 20037, USA; ${ }^{3}$ Department of Molecular Therapy, National Institute of Neuroscience, National Center of Neurology and Psychiatry, Tokyo, Japan; ${ }^{4}$ Department of Integrative Systems Biology, George Washington University School of Medicine and Health Sciences, Washington, DC 20037, USA and ${ }^{5}$ Department of Pediatrics, George Washington University School of Medicine and Health Sciences, Washington, DC 20037, USA

*Corresponding author: JK Jaiswal, Center for Genetic Medicine Research, Children's National Medical Center, 111 Michigan Avenue NW, Washington, DC 20010, USA. Tel: 202476 6456; Fax: 202476 6014; E-mail: jkjaiswal@cnmc.org

${ }^{6}$ These authors contributed equally to this work.

${ }^{7}$ Current address: Division of Clinical Review, Office of Bioequivalence, Office of Generic Drugs, Center for Drug Evaluation and Research, U.S. Food and Drug Administration, Silver Spring, MD 20993, USA

${ }^{8}$ Current address: Faculté de Médecine de la Timone, Université de la Méditerranée, Myologie translationnelle, Marseille, France

Abbreviations: DMD, Duchenne muscular dystrophy; DAPC, dystrophin-associated protein complex; LC, lengthening contraction; DDKO, Dysferlin-Dystrophin knockout; $\mathrm{PO}$, procion orange; PMO, phosphorodiamidate morpholino oligomer; SILAM, stable isotope labeling in mammal; IM, intramuscular

Received 02.6.16; revised 02.9.16; accepted 28.9.16; Edited by L Scorrano; published online 11.11.16 
increased calcium overload in dystrophic myofibers and mitochondria causes mitochondrial dysfunction, which in turn diminishes the repair ability of the dystrophic myofibers and results in their death.

To investigate the above hypothesis, we have analyzed the involvement of mitochondria in sarcolemmal repair of dystrophin-deficient myofibers. For this, we made use of two $m d x$ mouse models, both lacking dystrophin expression. The first one, $m d x-23$, has a mutation in the exon 23 of the Dmd gene in the $\mathrm{C} 57 \mathrm{BL} / 10$ mouse strain, and the second, $m d x-52$, lacks exon 52 of the Dmd gene on the C57BL/6 genetic background. We monitored the effect of dystrophin deficit on mitochondrial level, function, and myofiber repair. This showed that both $m d x$ mouse models have reduced mitochondrial activity and myofiber repair ability. These deficits in $m d x$ muscle were accompanied with increased level of dysferlin and associated sarcolemmal repair proteins. Deletion of dysferlin in the $m d x$ muscle showed that dysferlin-mediated sarcolemmal repair complements mitochondria-mediated sarcolemmal repair. By rescuing dystrophin expression using exon skipping and by acutely activating mitochondrial respiration, we evaluate the efficacy of these approaches to improve $m d x$ myofiber repair.

\section{Results}

Muscle proteome changes at disease onset in $\mathrm{mdx}$ mice. Dystrophin deficiency affects myofiber structure and increases mouse myofiber leakiness by 21 days of age. ${ }^{30,31}$ To monitor the earliest changes in the muscle proteome due to dystrophin deficit, we carried out quantitative proteomic analysis in triplicate of gastrocnemius muscles from $m d x$ mice (C57BL/10ScSn-Dmdmdx/J, henceforth referred to as $m d x-23)$ at postnatal days 21 and 28 and BL/10 wild type (WT) at postnatal day 28 by using the stable isotope labeling in mammal (SILAM) spike-in approach that we previously described. $^{29}$ Across all 9 samples, 1138 proteins were identified and accurately quantified (false detection rate (FDR) $q$-value $<0.01, \geq 2$ peptides, protein ratio obtained relative to SILAM spike-in $\geq 50 \%$ of the samples -5 out of 9 ). By hierarchical cluster analysis of the entire proteome, we found that 21-day-old $m d x$-23 co-clustered with the BL/10 WT muscle (Supplementary Figure S1a), but 28-day-old $m d x-23$ clustered independently from the BL/10 WT (Figure 1a). Unlike 21-day-old $m d x-23$, which did not yield any protein whose level differed significantly $(F D R<0.05)$ from $B L / 10$ WT, 28-day-old $m d x-23$ showed 249 proteins with significantly different levels (Supplementary Table S1). Accordingly, comparing average protein expression of 21-day-old $m d x-23$ and BL/10 WT showed a Pearson correlation coefficient of 0.93 (Supplementary Figure S1b), which was reduced to 0.81 when 28-day-old $m d x-23$ were compared with BL/10 WT (Figure $1 \mathrm{~b}$, proteins with FDR $(q)<0.05$ are shown in red). Thus onset of disease pathology at the protein level occurs between 21 and 28 days of age in $m d x-23$ mouse. To validate this further, we analyzed the $m d x-52$ mice, which are on C57BL/ 6 genetic background and have a targeted insertion in exon 52 of the Dmd gene. This insertion results in loss of expression of full-length dystrophin and of the shorter dystrophin isoforms, Dp140 and Dp260. ${ }^{32}$ Gastrocnemius muscle of 28-day-old BL/6 WT and $m d x-52$ were analyzed in triplicate and combined with the analysis of $\mathrm{BL} / 10$ and $m d x$ 23 muscle, which resulted in quantitative identification of 1178 proteins using the cutoff criterion listed above and mandatory protein detection in $>50 \%$ (7 out of the 12) samples. Hierarchical cluster analysis identified that 28-dayold $m d x-52$ clustered with age-matched $m d x-23$ mice but distinct from the age-matched parental WT strain C57BL/6 (Figure 1a). These analyses identify that, independent of genetic background and the mutant allele, the muscle proteome changes due to dystrophin deficiency occurs between postnatal days 21 and 28 . These changes corroborate with muscle histological changes, including the presence of small, centrally nucleated, regenerating fibers in both $\mathrm{mdx}$ models at 28 days (Figure 1c) but not at 21 days of age (Supplementary Figure S1c). With the similar proteomic changes, histopathology and age of disease onset in $m d x-23$ and $m d x-52$ models, we used both models in this study.

Proteins in dysferlin-mediated sarcolemmal repair, including annexins $\mathrm{A} 1$ and $\mathrm{A} 2$, are altered in $m d x$ muscle. ${ }^{29,33,34}$ Proteomic analysis confirmed altered annexin expression, but owing to the use of a stringent inclusion cutoff, low abundant proteins such as dysferlin, which we found increased in $m d x$ mice by $20-80 \%$, did not meet criterion for inclusion in the list of altered proteins (Supplementary Table S1). Owing to the known fragility of $m d x$ myofibers and the relevance of dysferlin and associated proteins in sarcolemmal repair, we analyzed the expression of sarcolemmal repair proteins by using western blotting (WB). This showed both $m d x-23$ and $m d x-52$, which lack dystrophin expression (Figures 1d and i), have increased abundance of dysferlin and associated membrane repair proteins at 28 days of age. Although dysferlin level in $m d x-23$ muscle increased by 1.5-fold (Figure 1e), annexin A1 and A2 increased by over 2 -fold (Figures if and g). A dysferlin-interacting protein, caveolin-3, which did not significantly increase in the 28-dayold $m d x-23$ muscle proteome, also appeared unchanged even by WB (Figure $1 \mathrm{~h}$ ). The $m d x-52$ muscle also showed 1.5-fold increase in dysferlin (Figure 1j), a 2-fold increase in annexin $A 1$ and $A 2$ level, and here caveolin-3 level was over 2-fold more (Figures 1k-m) than the matched WT C57BL/6 muscles. The coincident increase in dysferlin and interacting protein levels in $m d x$ models identified that, similar to DMD patients where dysferlin expression is increased, ${ }^{13}$ dystrophin deficit increases dysferlin-mediated sarcolemmal repair at the onset of disease symptoms.

Mitochondrial level and response to sarcolemmal injury is reduced in $\mathbf{m d x}$ muscle. Mitochondrial respiratory function is known to be reduced in $m d x^{35}$ and DMD patient muscles, ${ }^{36}$ and this was supported by our previous ${ }^{29}$ and the following findings. Of the 79 dysregulated organelle proteins identified, over a third localize to mitochondria (Supplementary Table S2). Proteins from other organelles, including peroxisomes, endosomes, lysosomes, nucleus, and Golgi, accounted for less than a third of the altered organellar proteins. To directly assess whether this reflects altered mitochondrial respiratory activity, we monitored Cytochrome $C$ enzyme activity in mitochondria isolated from 28-day-old 


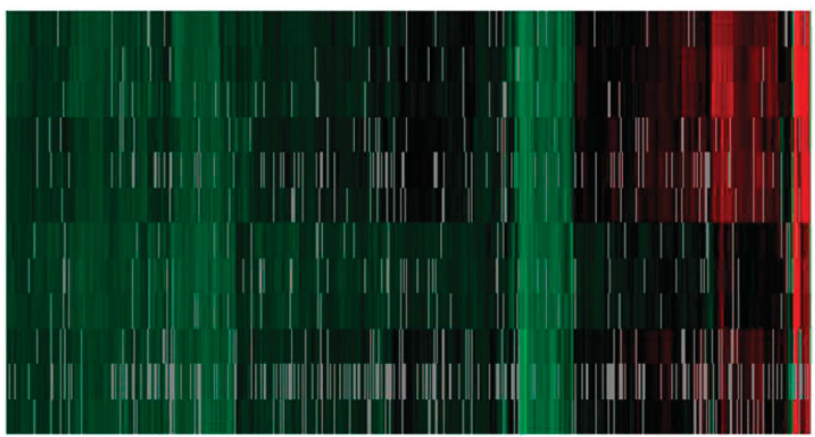

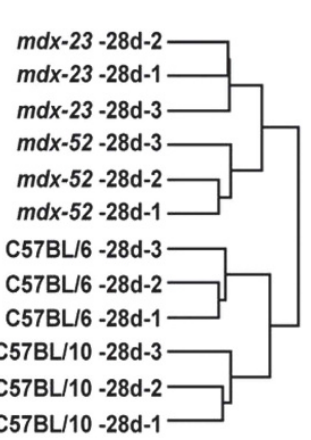

b

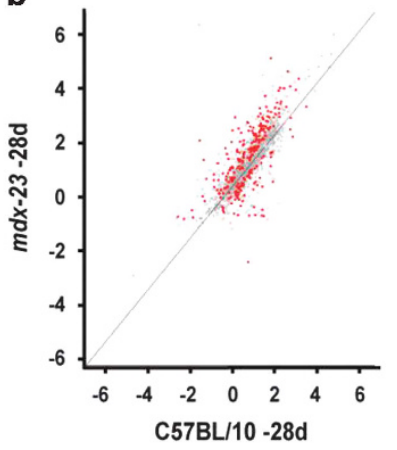

c
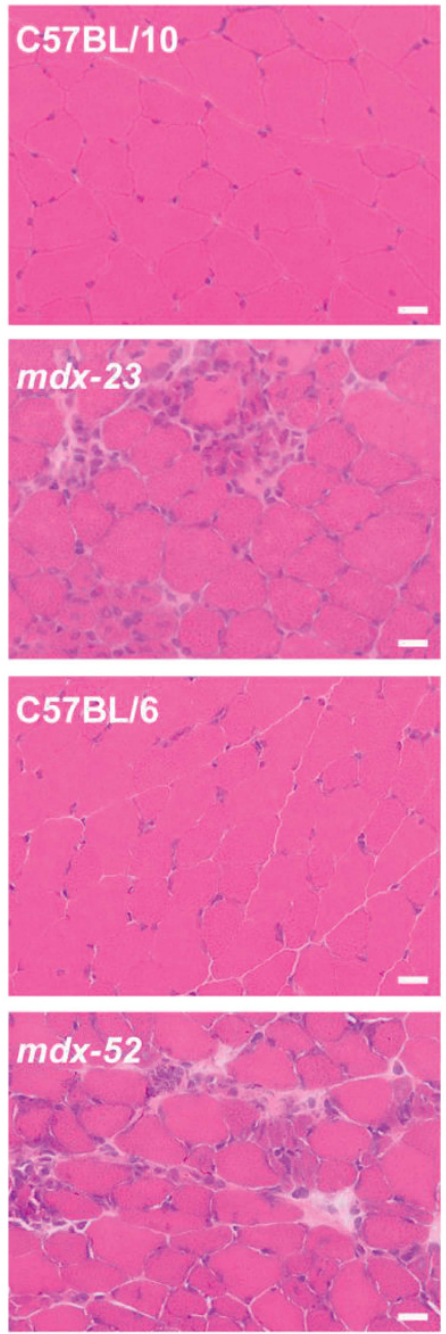

d
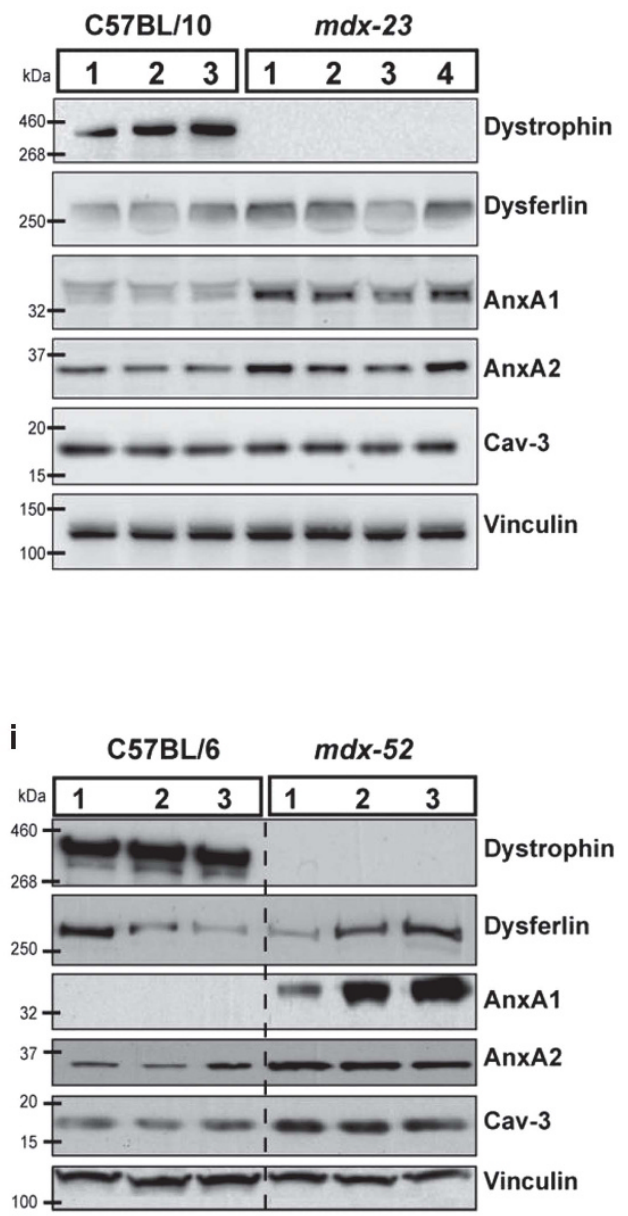

e
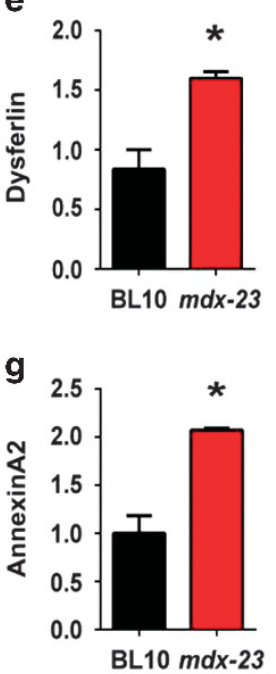

j

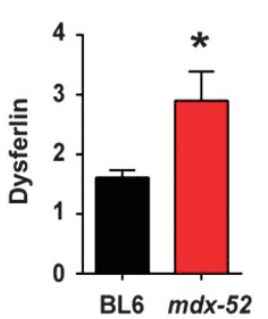

I

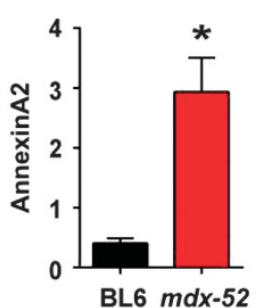

$\mathbf{f}$

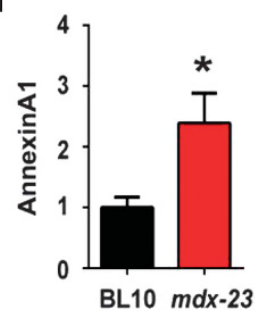

h

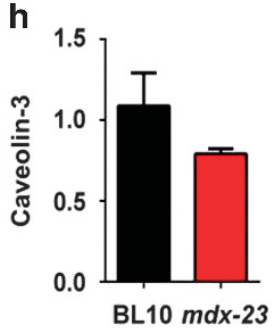

k

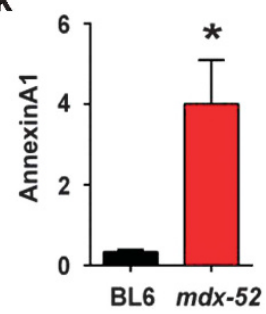

m

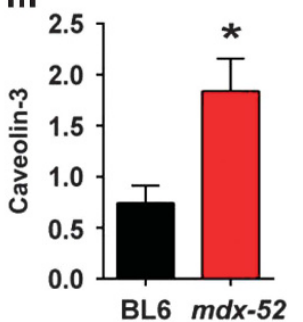

Figure 1 Cell membrane repair proteome changes at disease onset in $m d x$ mice. (a) Hierarchical cluster analysis of the 1178 proteins identified in 28-day-old $m d x-23, m d x$ 52 , and their respective age-matched WT strains. (b) Pearson correlation analysis of proteins from 28 -day-old $m d x-23$ and parental WT strain. Significantly altered proteins (FDR $q<0.05$ ) are shown in red. (c) Images showing histological features of gastrocnemius muscle cross-sections from 28-day-old $m d x-23$, $m d x-52$, and their respective age-matched WT strains. Note the presence of centrally nucleated, regenerating fibers and inflammatory foci in the muscles on $m d x$ cross-sections. Scale bar $=20 \mu \mathrm{m}$. (d) Image showing a WB of proteins from 28-day-old BL/10 WT $(N=3)$ and $m d x-23$ mice $(N=4)$. (e-h) Quantification of the expression level of dysferlin and associated proteins (normalized to the loading control and presented as the fold increase over the normalized average WT level) in the $m d x-23$ and BL/10 WT muscle. (i) Image showing WB of $m d x-52$ proteins at 28 days of age from three independent mice. ( $j-m$ ) Quantification of the expression level of dysferlin and associated proteins (normalized to the loading control and presented as the fold increase over the normalized average WT level) in $m d x-52$ and BL/6 WT. All graphs are presented as mean \pm S.D. ${ }^{*} P \leq 0.05$ by $t$-test 
a

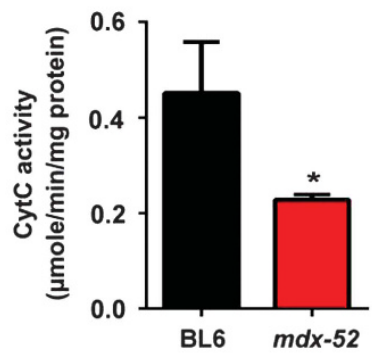

b

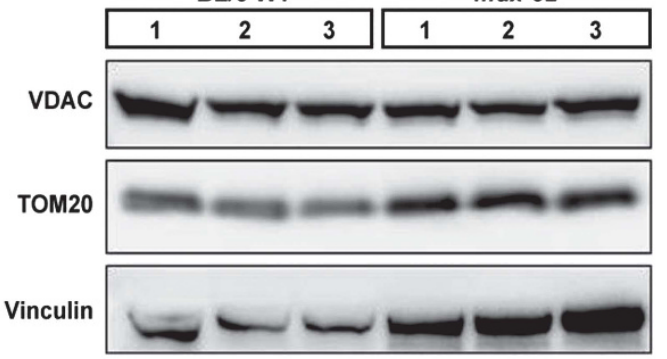

c

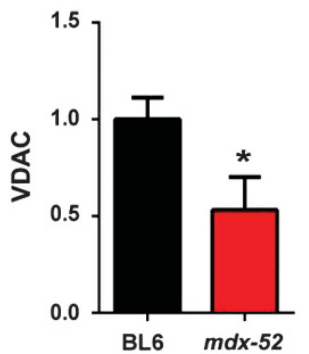

d

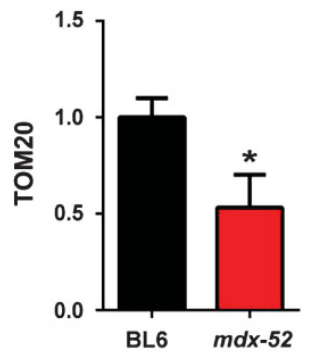

e

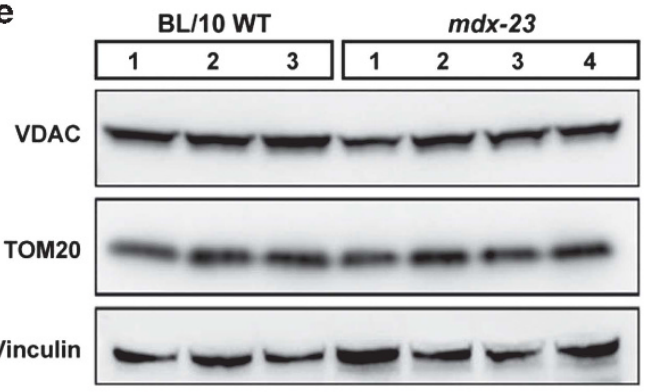

f

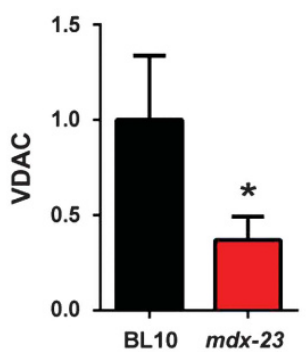

g

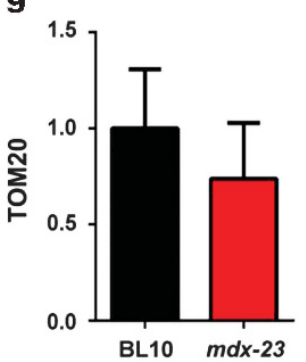

h

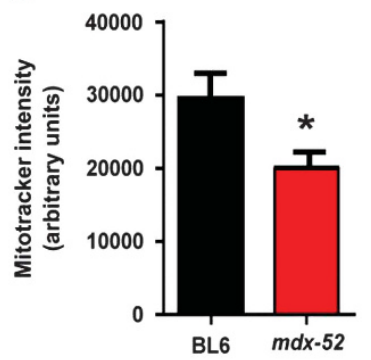

i

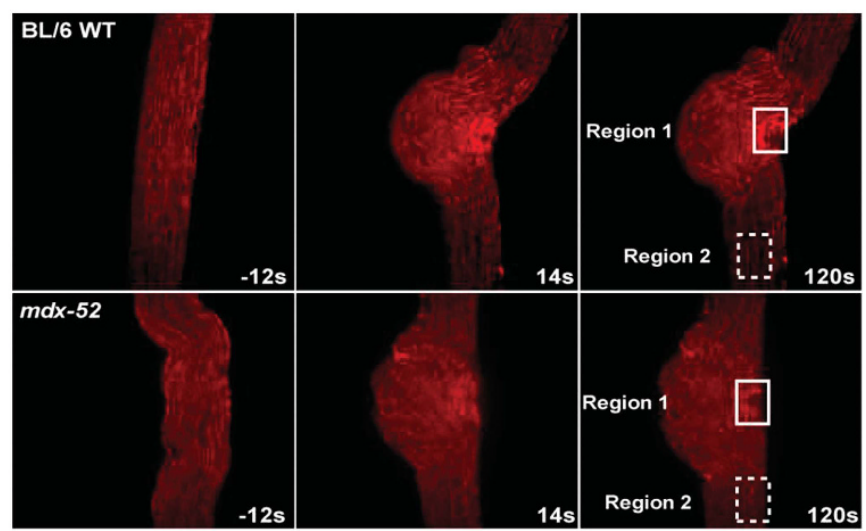

j

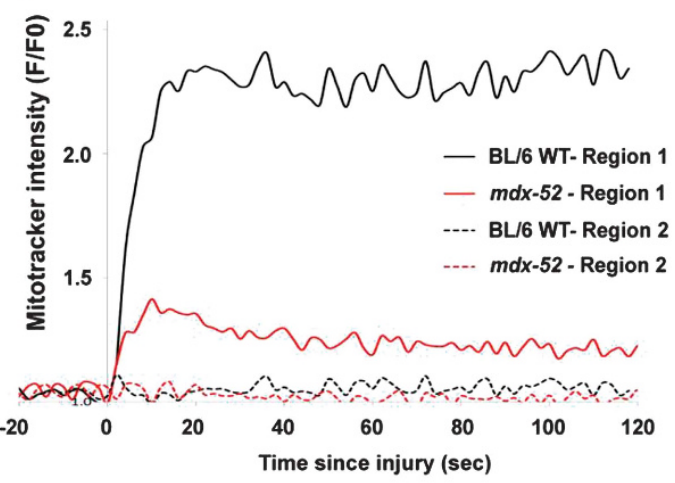

Figure 2 Mitochondria level and response to sarcolemmal injury are impaired in mdx muscle. (a) Mitochondria were isolated from 28 -day-old $m d x$-52 gastrocnemius muscle and Cytochrome oxidase kinetics was determined spectrophotometrically. Cytochrome $C$ activity was significantly decreased in $m d x-52$ muscle. (b) WB analysis of mitochondrial structural proteins VDAC and TOM20 in mdx-52 muscle from 28-day-old mice. Quantification of (c) VDAC and (d) TOM20 normalized to loading control (vinculin) shows increased expression of both these proteins over the normalized average WT level. (e) WB analysis of VDAC and TOM2O in the muscle from 28-day-old mdx-23. Quantification of (f) VDAC and (g) TOM20 protein levels normalized to loading control (vinculin) and presented as the fold increase over the normalized average WT level shows increased expression level. (h) Live imaging of mitochondrial activity in muscle fibers from 28-day-old $m d x-52$ mice labeled with mitochondrial activity sensor dye, MitoTracker CM-H2TMRos. (i) Time-lapse images of mitochondrial dynamics during focal laser injury of sarcolemma within the region marked by the box with solid line (Region 1). Region 2 (box with dotted line) marks a region away from the injury site. Note that accumulation peaked within $20 \mathrm{~s}$ of injury. (j) Quantification of mitochondrial accumulation indicated by increase in MitoTracker intensity. Note that mitochondrial accumulation occurred only at the site of injury (Region 1 ) and peaked within 20 s of injury and was significantly reduced in $m d x-52$ myofibers. ${ }^{*} P \leq 0.05$ by $t$-test

$m d x-52$ muscle. Compared with C57BL/6, mitochondria from $m d x-52$ muscles showed a 2-fold reduction in respiratory activity (Figure 2a). Next we examined whether the $m d x$ muscle show reduced mitochondria level. We quantified two independent mitochondrial structural proteins - voltagedependent anion channel (VDAC-1) and translocase of outer membrane 20 (TOM20). Compared with the respective parental WT mice, the level of both these proteins was decreased in the 28-day-old $m d x-52$ (Figures $2 b-d$ ) as well as $m d x-23$ muscle (Figures $2 \mathrm{e}-\mathrm{g}$ ). To monitor the mitochondrial membrane potential in situ in myofibers, we used
MitoTracker CM-H2TMRos, which localizes to mitochondria based on mitochondrial membrane potential, and becomes fluorescent upon being oxidized, thus allowing in situ monitoring of mitochondrial membrane potential. ${ }^{37,38}$ This showed that the 28-day-old $m d x-52$ myofibers have a significant in situ reduction in mitochondrial membrane potential (Figure 2h).

We have previously shown that sarcolemmal injury causes mitochondrial accumulation at the site of repair, which is compromised by mitochondrial depolarization. ${ }^{28}$ Owing to the reduced mitochondrial potential in $m d x$ muscle, we monitored 
mitochondrial response to sarcolemmal injury in $m d x$ myofibers. Within $20 \mathrm{~s}$ of sarcolemmal injury, mitochondria accumulated at the repair site (Figure 2i), but the extent of accumulation was significantly reduced in $m d x$ myofibers (Figure 2j). Recently, increase in autophagy has been linked to early compensatory stage of DMD progression. ${ }^{39}$ Thus we examined whether reduced $m d x$ mitochondrial potential and response to sarcolemmal injury is associated with increased mitophagic response. The level of the lysosomal membrane protein LAMP-1 is increased in $m d x$ muscle (Supplementary Figures S2a and b) and an increasing trend was observed for the autophagic marker - lipidation of LC3 (Supplementary Figures $\mathrm{S} 2 \mathrm{a}$ and $\mathrm{c}$ ). Thus disease onset in $m d x$ muscle involves mitochondrial dysfunction and enhanced autophagy may aid to clear these mitochondria.

\section{Dystrophin-deficient $\mathrm{mdx}$ myofibers repair poorly in} response to sarcolemmal injury. With the increased fragility of $m d x$ myofibers and compromised mitochondrial response to sarcolemmal injury, we hypothesized that increased dysferlin-dependent membrane repair proteins aid with the repair of $m d x$ myofibers. To assess sarcolemmal repair, following laser injury, we imaged entry of a membrane impermeable lipid-binding dye FM1-43 into the myofiber of 28-day-old $m d x-52$, as before. ${ }^{33,40}$ Unlike the myofibers from the parental BL/ 6 WT, dye entry into $m d x$ myofibers continued steadily (green staining) eventually causing myofiber hypercontraction (Figures $3 a$ and $b$ ). Most of the $m d x-52$ myofibers hypercontracted, preventing quantification of the FM-dye entry kinetics as we have carried out in other studies. ${ }^{33,41}$ Only $25 \pm 9 \%$ of $m d x-52$ myofibers $(N=34)$ showed the same low FM dye entry that was seen in the WT myofibers (Figures $3 \mathrm{~b}$ and $\mathrm{c}$ ). This is in contrast to BL/6 WT myofibers where $66 \pm 8 \%(N=22)$ of myofibers repaired (Figures $3 b$ and $\mathrm{c}$ ).

Muscle contraction induces greater sarcolemmal damage to $m d x-23$ myofibers, ${ }^{4}$ but this has not been tested for the $m d x$ 52 muscles. We thus evaluated the ability of $m d x-52$ mice myofibers to repair from ex vivo eccentric injury caused by $10 \%$ lengthening contraction (LC). After the very first eccentric injury, the extensor digitorum longus (EDL) muscles from 28day-old $m d x-52$ mice exhibited a greater loss in the contractile force as compared with the parental BL/6 WT muscle (Figure 3d). This loss was even greater following subsequent round of LC-induced injuries and by the ninth LC injury, the loss in contractile force was $35 \%$ greater in $m d x-52$ muscle as compared with the BL/6 WT (Figure 3d). To assess whether greater force loss owing to LC injury correlated with similar increase in sarcolemmal damage, the muscles were incubated in cell-impermeable dye procion orange (PO). A single $\mathrm{LC}$ injury to EDL muscles caused PO labeling of $8.8 \pm 8.6 \mathrm{mdx}$ myofibers/muscle section, which increased with additional LC injures (Figures $3 e$ and $f$ ). In contrast, even after 9 LC injuries only $4.3 \pm 2.6 \mathrm{BL} / 6 \mathrm{WT}$ myofibers were PO labeled in each EDL muscle section (Figure $3 \mathrm{~g}$ ). Thus two independent methods of myofiber injury show greater loss in sarcolemmal integrity in the dystrophin-deficient $m d x$ myofibers. This suggests that absence of dystrophin and subsequent mitochondrial pathology impairs repair of $m d x$ myofibers despite the upregulation of dysferlin and associated membrane repair proteins.

Dystrophin-deficient myofibers rely on dysferlin for sarcolemmal repair. In view of the reduced mitochondrial function and poor repair of $m d x$ myofiber sarcolemmal injury, we hypothesized that the increased expression of the dysferlin-mediated sarcolemmal repair proteins offsets some of repair deficit of dystrophin-deficient myofibers. To test this, we crossed $m d x-52$ and $\mathrm{B} 6 \mathrm{~A} / \mathrm{J}$ mice to generate congenic C57BL/6 mice lacking both dysferlin and dystrophin protein expression (Dysferlin-Dystrophin Knockout (DDKO)). PCR genotyping and WB analysis confirmed that dystrophin and dysferlin genes are mutated in these mice and neither of these proteins are expressed in the skeletal muscle of the DDKO mice (Figures $4 \mathrm{a}$ and $\mathrm{b}$ ). These mice grow to adulthood and breed to produce healthy litters. Loss of dysferlin in B6A/J mice does not cause histological and functional deficit for the first 2 months of life. ${ }^{42}$ However, histological analysis showed that DDKO muscle exhibit greater pathology than the dysferlin-and-dystrophin-deficient $\mathrm{BL} / 6$ muscle (Figure 4c) and have high level of proinflammatory marker interleukin-1 $\beta$ (Figure $4 d$ ).

To investigate the relevance of dysferlin expression for the repair of injured $m d x$ myofibers, we monitored sarcolemmal repair kinetics of DDKO mice at 28 days of age, when lack of dysferlin alone does not result in muscle pathology. ${ }^{43}$ In contrast to the $m d x$ myofibers where $21 \pm 8 \%$ of myofibers repaired (replicating the findings in Figure 3 ), only $8 \pm 4 \%$ of the DDKO myofibers repaired ( $N=29$ myofibers) (Figure $4 \mathrm{e}$ ). This $\sim 3$-fold decrease in myofiber repair ability suggests that increased dysferlin expression in $m d x$ muscle is crucial for the limited ability of $m d x$ myofiber repair.

To further assess the role of dysferlin in $m d x$ myofiber repair, we examined the contractile force and the recovery of EDL muscle from LC injury. DDKO muscles have lower contractile force than C57BL/6 and $m d x-52$ mice (Figure 4f) and showed increased susceptibility to LC-induced damage. Following 9 successive LC injuries, DDKO muscles lost $>80 \%$ of original contractile force as compared with the loss of $60 \%$ in $m d x-52$ and of $<30 \%$ in the WT EDL muscle (Figure 4g). By PO labeling following LC injury, we found that greater loss of contractile force in DDKO muscle matches with nearly 2-fold and 10-fold more PO-labeled DDKO fibers as compared with $m d x$ and WT EDL muscles, respectively (Figure 4h). To assess whether the poor repair of DDKO myofibers involves further reduction in the ability of mitochondria to accumulate at the site of injury, we monitored mitochondrial response to sarcolemmal injury in DDKO myofibers and found it was similar to what we observed in $m d x$ myofibers (Figures $4 \mathrm{l}$ and $\mathrm{j}$ versus Figures $2 \mathrm{l}$ and j). The above results demonstrate that presence of dysferlin in the young $m d x$ mice is critical for myofiber repair and thus dysferlin-mediates sarcolemmal repair independently of mitochondria. Poor sarcolemmal repair of the dystrophindeficient skeletal muscle due to the mitochondrial deficit is offset in part by the increase in dysferlin-mediated repair machinery. 
Effect of exon skipping and increased mitochondrial respiration on $\mathrm{mdx}$ sarcolemmal repair. As lack of dystrophin is the primary defect responsible for the mitochon- drial dysfunction and poor repair of $m d x$ myofibers, we tested whether acute expression of a dystrophin protein by exon skipping therapy would improve the ability of $m d x$ myofibers

a
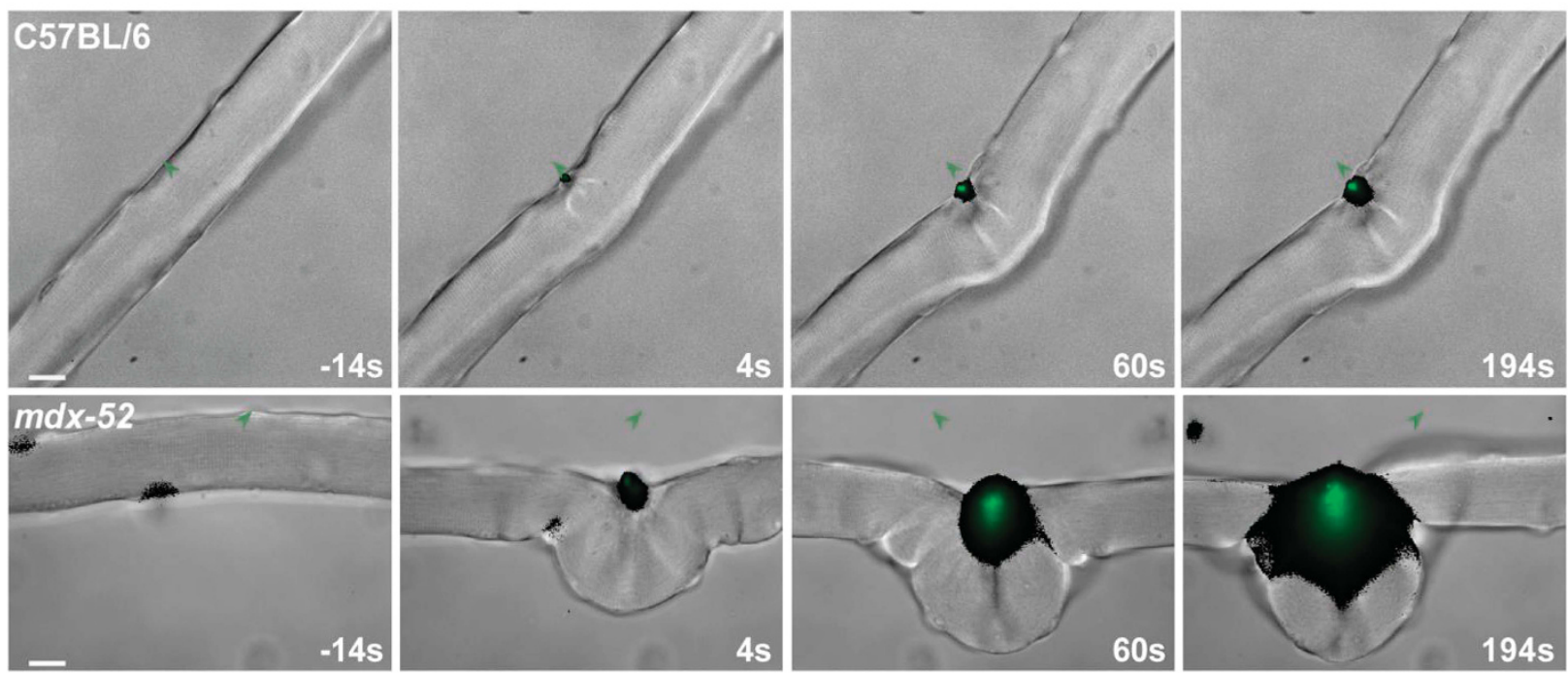

b

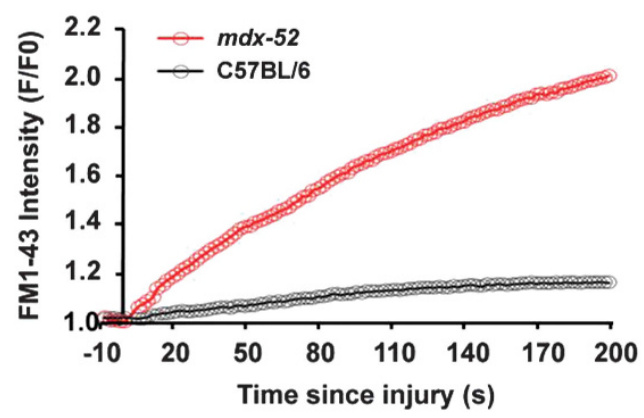

$\mathbf{e}$

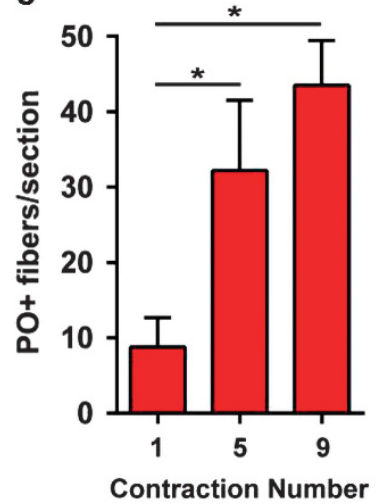

f
C

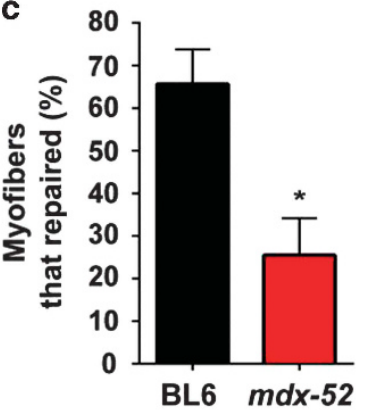

d

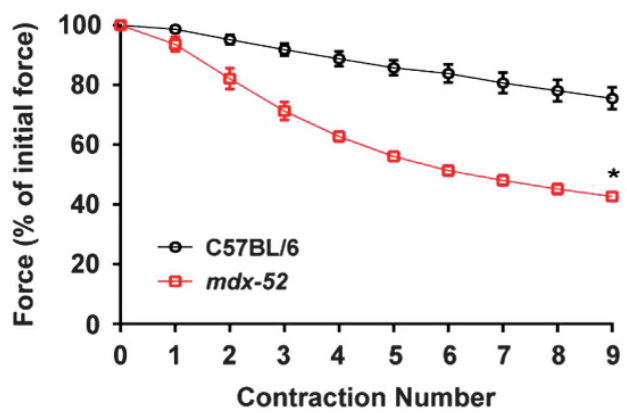

g
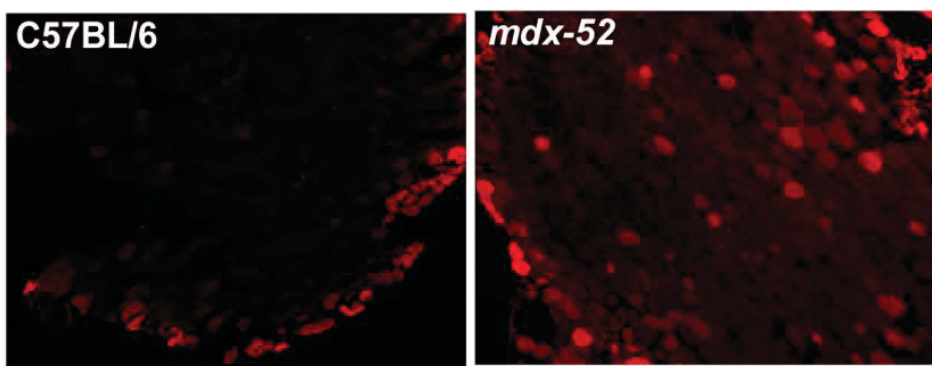

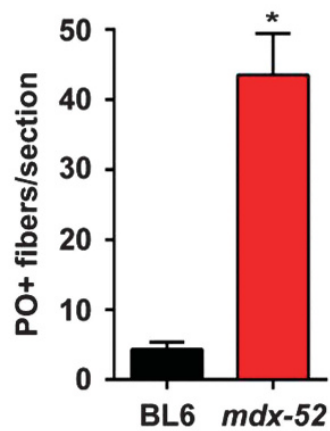

Figure 3 Dystrophin-deficient myofiber sarcolemma repair poorly from injury. (a) Sarcolemmal repair was monitored by live imaging after pulsed laser injury in the presence of membrane impermeable lipid-binding dye FM1-43. At $60 \mathrm{~s}$ after injury, BL/6 WT myofibers repaired, stopping dye entry. However, mdx myofibers failed to repair as evidenced by continued dye entry, which caused hypercontraction of the myofibers. (b) Plot showing the kinetics of injury-triggered increase in FM1-43 fluorescence in myofibers shown in panel (a). (c) Myofiber repair following laser injury was quantified in 34 myofibers (from 4 mice). Only $25 \pm 9 \%$ of $m d x-52$ fibers repaired, as compared with $66 \pm 8 \%$ of BL/6 WT fibers ( $N=22$ myofibers from 3 mice). (d) Repair of myofibers following mechanical injury was monitored by LC injury of EDL muscle from 28-day-old mdx-52. The plot shows loss in contractile force following each LC injury, which was greater in $m d x-52$ muscle as compared with the C57BL/6. (e) Quantification of PO uptake by $m d x-52$ myofibers following successive rounds of $10 \%$ LC injury. Note that PO labeling increases with the number of LCs. (f) Representative images and (g) quantification of PO labeling of myofibers following nine contraction injuries. Compared with the WT muscle (median $=2.5$ fibers/EDL), more $m d x-52$ myofibers (median $=46$ fibers/EDL) are labeled with PO. Graphs are presented as mean \pm S.D. ${ }^{*} P \leq 0.05$ by $t$-test 
a
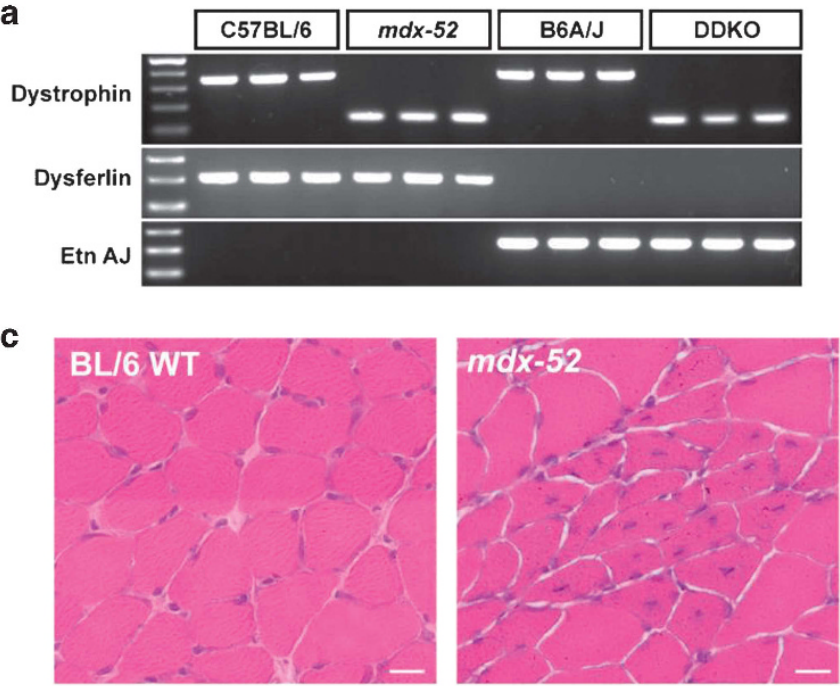

b
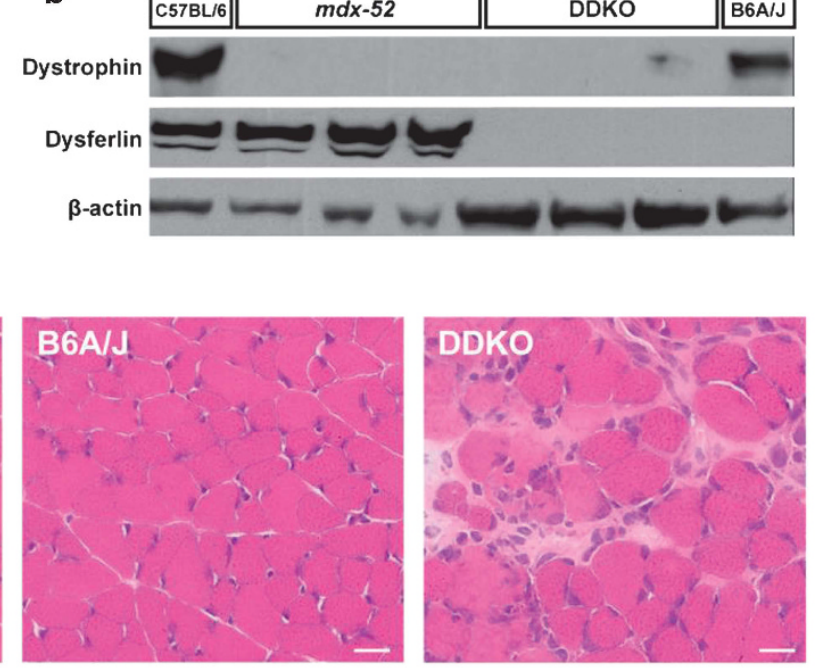

d
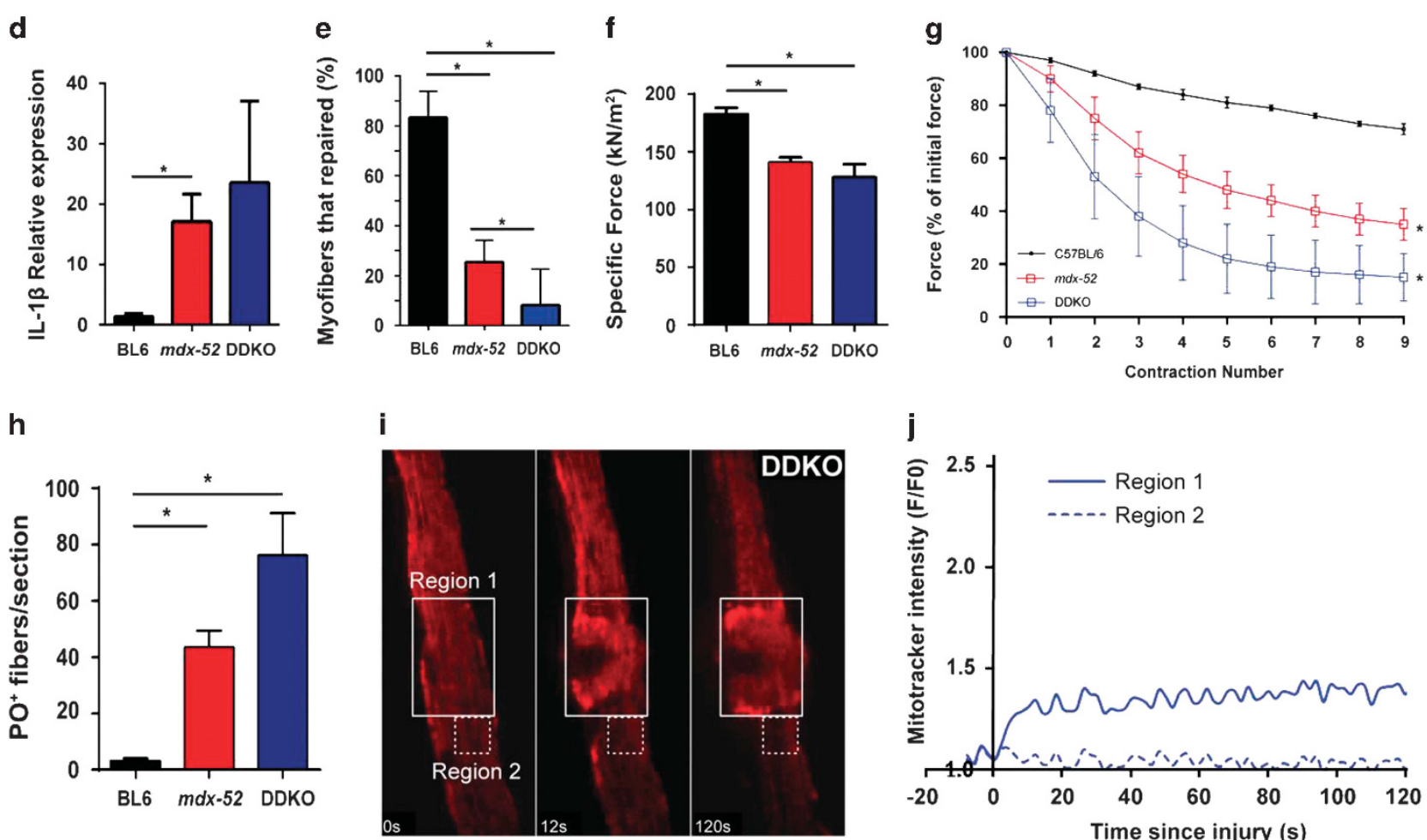

j

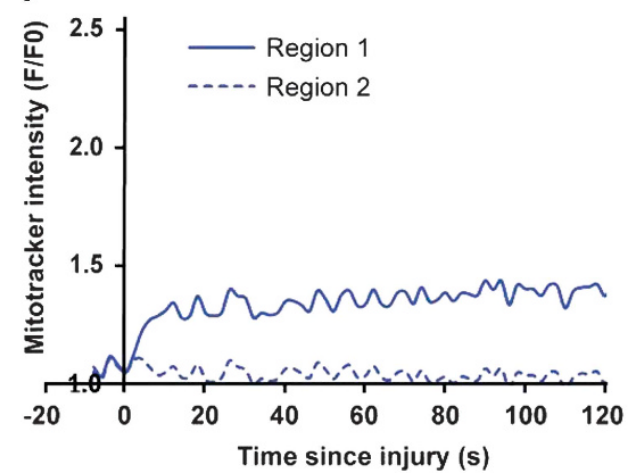

Figure 4 Dysferlin is essential for sarcolemmal repair of dystrophin-deficient myofibers. C57BL/6 DDKO were generated by crossing mdx-52 and B6A/J mice and confirmed by (a) genomic DNA PCR and (b) WB analysis. (c) Images showing histological features of TA muscles from 28-day-old mice. Note the significantly enhanced muscle pathology in DDKO muscles. Scale bar $=20 \mu \mathrm{m}$. (d) Quantification of the relative expression of interleukin IL-1 $\beta$ in 28-day-old quadriceps muscles from BL/6 WT, $m d x-52$, and DDKO. (e) Myofiber repair following laser injury was quantified in 29 DDKO myofibers (from 3 mice). Only $8 \pm 4 \%$ of the DDKO myofibers were able to repair compared with $21 \pm 8 \%$ of $m d x-52$. (f) Contractile force generation by the EDL muscle from 28-day-old BL/6 WT, $m d x-52$, and DDKO mice. (g) Loss in muscle contractile force following mechanical injury by $10 \%$ LC was monitored for EDL muscle from 28-day-old BL/6 WT, $m d x-52$, and DDKO mice. Note the greatest loss in contractile force in DDKO mice. (h) Quantification of PO-labeled myofibers following nine LC injuries was significantly greater in DDKO than $m d x-52$ mice. (i) Time-lapse images of mitochondrial dynamics during focal laser injury of DDKO sarcolemma within the region marked by the box with solid line (Region 1). Region 2 (box with dotted line) marks a region away from the injury site. (j) Quantification of mitochondrial accumulation indicated by MitoTracker intensity. Note that mitochondria fail to accumulate at the site of injury (Region 1 ). ${ }^{*} P \leq 0.05$ by one-way analysis of variance (with Bonferroni correction posttest)

to repair. We have established that a single high bolus $(800 \mathrm{mg} / \mathrm{kg})$ systemic delivery of antisense oligonucleotide (phosphorodiamidate morpholino oligomer (PMO)) reexpresses dystrophin in $m d x-23$ mice. ${ }^{44}$ One month after administering PMO to 28-day-old $m d x$-23 mice $(N=6)$, the highest dystrophin expression in the EDL muscle was $2 \%$ of the WT (C57BL/10) (Supplementary Figures S3a and b). This increase in protein expression only marginally $(5.9 \%)$ 
a
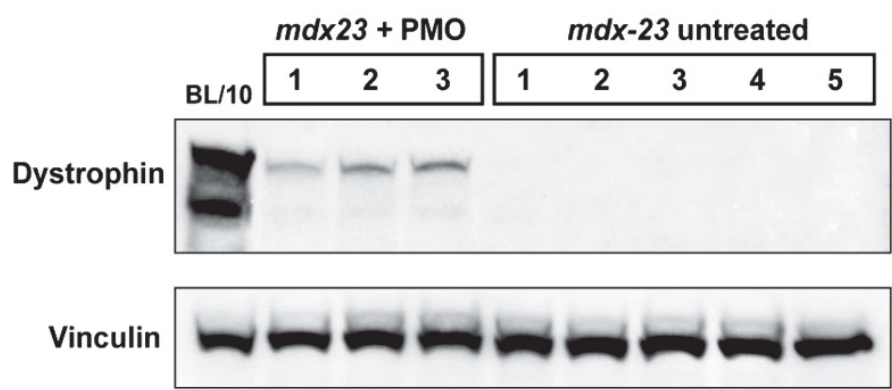

b

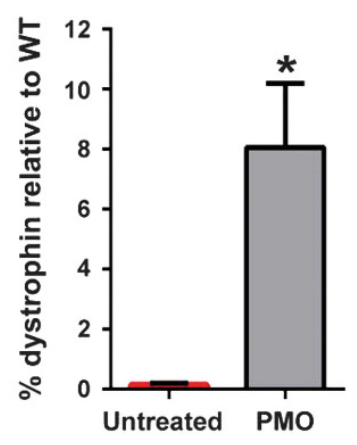

c

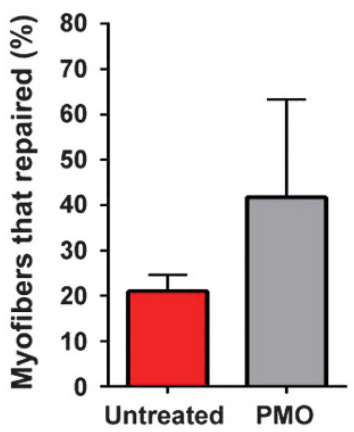

e

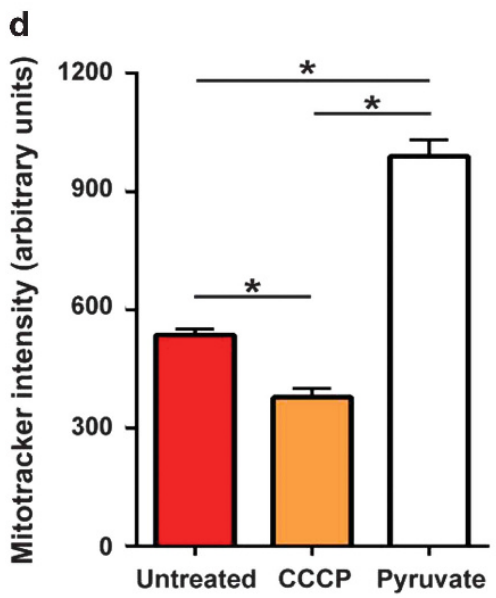

g

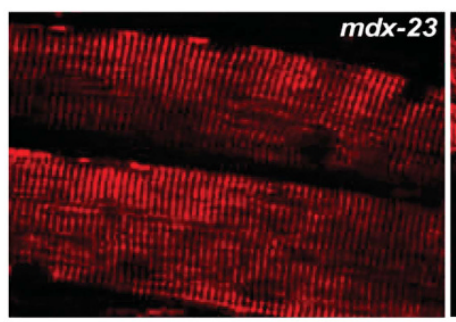

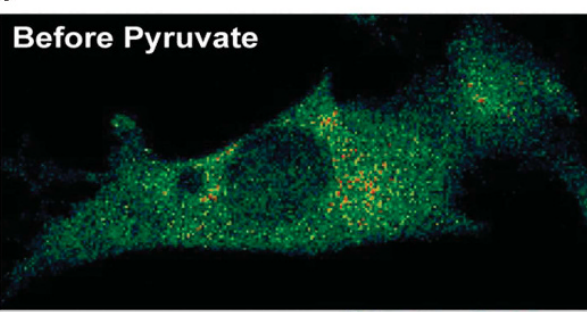

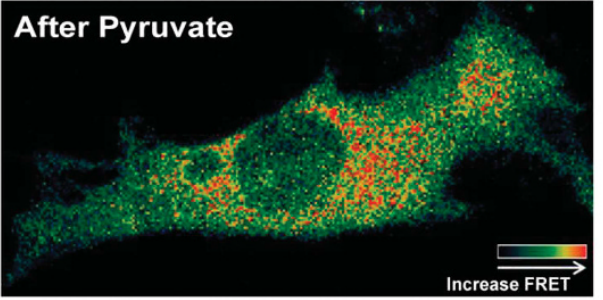

h

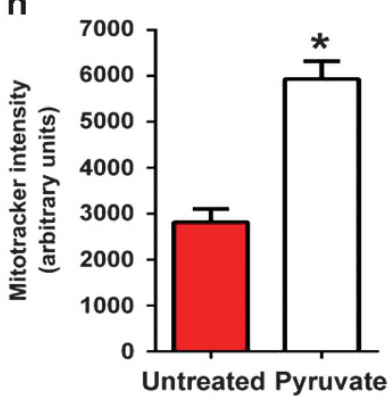

f

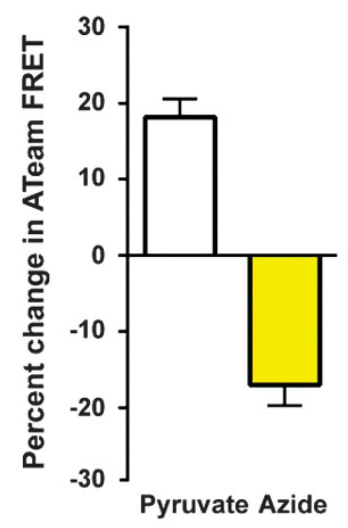

i

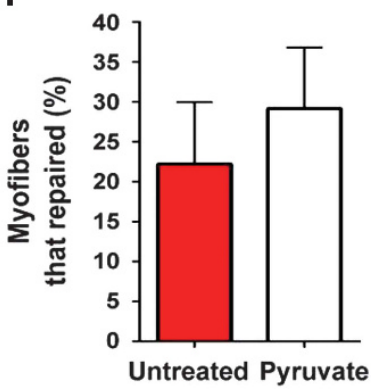

Figure 5 Effect of increased dystrophin expression and mitochondrial activity on $m d x$ sarcolemmal repair. (a) WB of dystrophin protein from FDB of three $m d x-23$ animals 2 weeks after three IM injections of PMO. (b) Dystrophin level was quantified by normalizing the protein levels to loading control and presented as a percentage of the total BL/10 WT dystrophin level. (c) Quantification of FDB myofibers that repaired following focal laser injury. Note that $21 \pm 2 \%$ of $m d x-23$ fibers ( $N=30$ fibers from 3 mice) were able to repair, while $42 \pm 12 \%$ of AO-treated $m d x-23$ myofibers repaired ( $N=26$ myofibers from 3 mice). (d) Quantification of cellular MitoTracker CM-H2TMRos intensity following CCCP or pyruvate treatment of $\mathrm{C} 2 \mathrm{C} 12$ myoblasts ( $N>134$ cells each). (e) Representative pseudocolored live cell ATeam FRET image of myoblasts before and after pyruvate treatment to increase cellular ATP production. (f) Quantification of ATeam FRET after pyruvate or azide treatment ( $N>10$ cells each). (g) Representative live images of mitochondria stained with MitoTracker CM-H2TMRos, before (left) and after (right) the mdx-23FDB muscles were treated for 25 min with $100 \mathrm{mM}$ pyruvate. (h) Quantification of mitochondrial labeling intensity ( $N>30$ myofibers from 2 mice). (i) Myofiber repair following laser injury. A total of $22.2 \pm 7.7 \%$ of $m d x-23$ untreated fibers ( $N=36$ myofibers from 2 mice) were able to repair following focal sarcolemmal injury, while $29.2 \pm 7.65 \%$ of pyruvate-treated $m d x-23$ myofibers were able to repair ( $N=49$ myofibers from 2 mice). All the data are presented as mean percentages \pm S.D. ${ }^{*} P \leq 0.05$ by t-test

increased EDL specific force but not its recovery from LC injury (Supplementary Figure S3c).

To further enhance exon skipping efficacy, flexor digitorum brevis (FDB) muscles from $m d x-23$ mice were treated with three, weekly intramuscular (IM) PMO injections at $20 \mathrm{mg} /$ muscle. Two weeks after the last injection, dystrophin level was measured and was $8 \pm 2.12 \%$ of the BL/10 WT level
(Figures 5a and b). Using laser injury, we assessed the effect of this increased dystrophin expression on sarcolemmal repair. As with the $m d x-52$ myofibers (Figure 3 ), $21 \pm 2 \%$ of $m d x-23$ fibers ( $N=30$ myofibers) repaired following focal sarcolemmal injury (Figure $5 \mathrm{c}$ ), which doubled to $42 \pm 12 \%$ $(N=26$ myofibers) upon dystrophin re-expression (Figure $5 c$ ). The repair response between the muscles from different 


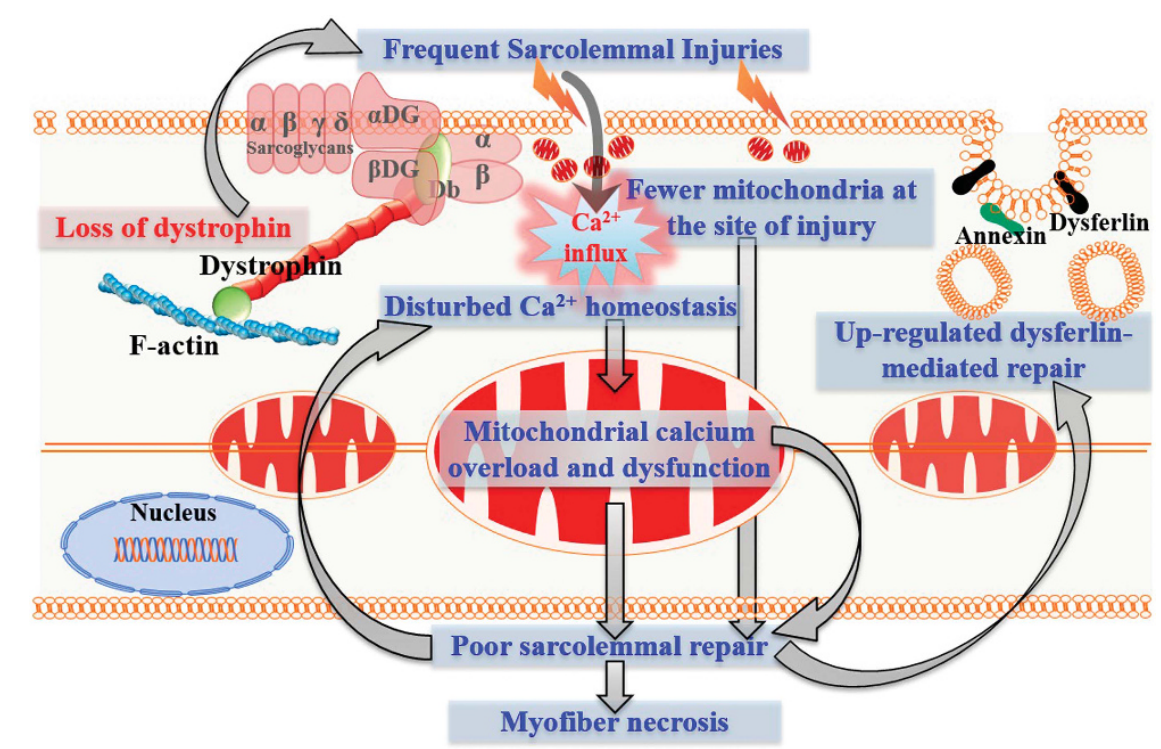

Figure 6 A model for the contribution of mitochondria in the damage of dystrophin-deficient myofiber. Absence of dystrophin increases susceptibility of myofiber sarcolemma to contraction-induced damage. Frequent sarcolemmal damage repeatedly increases cellular calcium load, which is taken up in part by the mitochondria. This calcium overload contributes to the decrease in mitochondrial activity, in accumulation at the site of injury and in mitochondrial level (potentially by mitophagy). These mitochondrial pathologies compromise the repair ability of the dystrophin-deficient myofibers, creating a positive feedback loop that results in greater necrosis of the dystrophin-deficient myofibers and increased muscle degeneration. Upregulation of dysferlin and dysferlin-related proteins is a compensatory response to this poor sarcolemmal repair, which activates the vesicular machinery for the repair of injured dystrophic sarcolemma. This increase in dysferlin-mediated repair machinery slows but fails to rescue the poor repair of dystrophic sarcolemma caused by the decline in mitochondrial function and their ability to accumulate at the site of sarcolemmal damage

PMO-treated mice was significantly heterogeneous owing to which, despite the 2-fold improvement in myofiber repair, the increase was not statistically significant.

Providing pyruvate as the substrate for mitochondrial respiration improves force production by dystrophin-andutrophin-deficient muscle. ${ }^{45}$ To test whether pyruvate treatment increases mitochondrial respiration in the $m d x$ myofibers, we again made use of the CM-H2TMRos dye. Although depolarizing mitochondria with CCCP decreased, $100 \mathrm{mM}$ pyruvate increased CM-H2TMRos fluorescence (Figure $5 \mathrm{~d}$ ). Independently, using a genetically encoded ATP sensor ATeam, ${ }^{46}$ we monitored change in ATP production at single cell level. Pyruvate increased, whereas the respiratory chain poison Azide decreased ATP production as indicated by the ATeam FRET signal (Figures $5 e$ and f). Pyruvate-mediated increase in mitochondrial potential and ATP production established that $100 \mathrm{mM}$ pyruvate treatment is sufficient to boost energy production by $m d x$ mitochondria (Figure $5 d$ ). We next tested whether increasing mitochondrial bioenergetics can improve $m d x$ sarcolemmal repair. Treating muscles with $100 \mathrm{mM}$ pyruvate increased CM-H2TMRos intensity by 2-fold (Figures $5 \mathrm{~g}$ and $\mathrm{h}$ ) but did not significantly increase the EDL-specific force: $126.7 \pm 25.94$ in untreated versus $141.33 \pm 14.83 \mathrm{KN} / \mathrm{m}^{2}$ in pyruvate-treated $(N=6$ muscles each), nor improved mitochondrial accumulation at the site of injury. We next assessed the effect of pyruvate treatment on myofiber repair following laser injury. A total of $22.2 \pm 7.7 \%$ of untreated $m d x-23$ myofibers $(N=36)$ repaired and pyruvate treatment did not significantly improve myofiber repair $(29.2 \pm 7.65 \%$ myofibers; $N=49)$ (Figure $5 \mathrm{i})$. Thus, while dystrophin re-expression holds the potential for improving mdx myofiber repair ability, once mitochondrial dysfunction sets in, an acute increase in respiratory activity of these dysfunctional mitochondria is insufficient to improve dystrophic myofiber repair.

\section{Discussion}

Our investigation of early events during disease initiation due to dystrophin-deficit has identified poor sarcolemmal repair as an early consequence of dystrophin deficit. We propose a model to explain the underlying mechanism for the poor repair (Figure 6). Calcium entry owing to sarcolemmal tears caused by the dystrophin-deficient sarcolemma fragility and by the calcium leak channels results in calcium overload in the dystrophic muscle. ${ }^{9,18-20}$ Mitochondria buffers part of this calcium overload. This causes decline in mitochondrial function and mitochondrial loss by autophagy. Dysfunction and loss of mitochondria causes poor myofiber repair, which further increases calcium overload setting up a positive feedback loop for dystrophic myofiber necrosis (Figure 6). A compensatory increase in dysferlin-mediated sarcolemmal repair offers relief but fails to rescue sarcolemmal repair defect due to mitochondrial dysfunction in dystrophic myofibers. Dystrophin deficit in $m d x-23$ mice leads to structural and histopathological changes between 2 and 4 weeks of age. ${ }^{30,31,45}$ This may contribute to the reduced mitochondrial accumulation at the site of injury (Figures 2 and 6).

In agreement with early changes in $m d x$ muscle, we find that $m d x$ muscle proteome is altered by 3-4 week of age and includes reduced level and function of mitochondria. In addition to energetic deficit and oxidative damage that has 
been associated with mitochondrial deficit in dystrophindeficient muscle, we show that this also results in poor sarcolemmal repair. Poor repair is evident not only in isolated myofibers but also in intact muscles, such that 28-day-old $m d x$ mouse muscle suffers greater sarcolemmal damage by eccentric contraction (Figure 3). Enhanced dye uptake by dystrophin-deficient myofibers upon a single eccentric contraction identifies that poor sarcolemmal repair contributes to muscle force loss by eccentric contractions (Figure 3). Mitochondrial role in sarcolemmal repair is in agreement with reports that upregulating PGC1a in $m d x$ mice improves myofiber recovery from LC injury and reduces muscle degeneration. ${ }^{47-49}$ The underlying mechanism for the role of mitochondria has not been elucidated but may involve regulation of myofiber bioenergetics and calcium handling. This is supported by studies showing that increased PGC1a expression in $m d x$ mice improves metabolism and mitochondrial capacity to buffer $\mathrm{Ca}^{2+}$ and reduces $\mathrm{Ca}^{2+}$-dependent protease activity. ${ }^{47,50,51}$

Our results show that mitochondria-mediated sarcolemmal repair is distinct from dysferlin-mediated repair. Although mitochondria-mediated repair declines within the first 4 week of age in $m d x$ mice, dysferlin-mediated repair is increased by this age. Previous studies with 6-month-old DDKO mice have found more severe muscle pathology of these mice than either of the parental knockouts. ${ }^{12,52}$ But, as dysferlin deficit causes muscle pathology in 6-month-old mice, the severe pathology of 6-month-old DDKO mice could arguably be due to two simultaneous diseases. However, we find that the dysferlin deficit increases muscle pathology of the $m d x$ mice at 28 days of age, when lack of dysferlin alone does not cause detectable muscle pathology. ${ }^{43}$ Thus, owing to poor mitochondriamediated repair, dysferlin-mediated repair is increased to facilitate repair of dystrophin-deficient myofibers. Simultaneous upregulation of dysferlin-related membrane repair proteins, including annexin A1 and annexin A2 in the mouse, and of dysferlin, annexin A1 and mitsugumin 53 in DMD patients independently supports this mechanism and explains how genetic ablation of dysferlin can significantly worsen the phenotype of dystrophin-deficient muscle. ${ }^{12,13,52,53}$

To investigate whether dystrophin re-expression could reverse the sarcolemmal repair deficit, we used exon skipping therapy to restore dystrophin, which is known to improve dystrophic muscle strength in a dystrophin expression leveldependent manner. ${ }^{54,55}$ Antisense oligonucleotides conjugated to a cell-penetrating peptide restores dystrophin expression up to $15 \%$ of the healthy level and protects dystrophic $m d x$ muscle against eccentric contraction-induced injury. ${ }^{54}$ However, with reduced toxicity, FDA approved use of $\mathrm{PMO}$ as an exon skipping therapy for DMD. We observed that $\mathrm{PMO}$ caused an $8 \%$ increase in dystrophin level, which increased sarcolemmal repair by 2 -fold. However, large heterogeneity in $\mathrm{AO}$-induced dystrophin re-expression between myofibers causes significant variability in myofiber repair. These results provide a proof-of-principle demonstration that a large and/or homogenous increase in dystrophin expression could improve the repair ability of dystrophic myofibers. Further, we identified that merely increasing the mitochondrial respiratory activity (by the use of pyruvate, the limiting substrate for the TCA cycle) does not improve $m d x$ myofiber repair. Our findings that exon skipping-mediated restoration of dystrophin expression shows its potential to improve membrane repair, but this requires reduced dysfunction and increased biogenesis of mitochondria, which is achieved using exercise mimetics. ${ }^{47,50}$ Thus combined use of exercise mimetics and exon skipping with PMOs may be a potent therapy for improving sarcolemmal repair. In summary, our findings demonstrate a nexus between dystrophin deficit, mitochondrial dysfunction, and myofiber necrosis and identify this nexus as a novel therapeutic target to improve myofiber survival in DMD.

\section{Materials and Methods}

Animal husbandry and live imaging of myofiber repair. All animal procedures were conducted in accordance with guidelines for the care and use of laboratory animals as approved by the Institutional Animal Care and Use Committee. C57BL/6 and C57BL/10 control mice and $m d x-52$ and $m d x-23$ mice were bred in-house and used for all experiments. All animals were maintained in an individually vented cage system under a controlled $12 \mathrm{~h}$ light/dark cycle with free access to food and water. Dysferlin-deficient-B6A/J and dystrophin-deficient- $m d x-52$ mice were each created on the BL/6 genetic background and were thus used here to generate DDKO mice. The F1 offspring were intercrossed, and progeny that genotyped as double heterozygous were used to generate a stock of mice that were null at both alleles and these animals were used to generate the DDKO colony. To identify mutant dysferlin and dystrophin genes, PCR genotyping was performed as previously described. ${ }^{32,43}$ Immunoblotting was also performed to confirm the absence of proteins in the skeletal muscle. To assess histological features, gastrocnemius muscle tissues were obtained from C57BL/10, $m d x-23$, C57BL/6, $m d x-52$, and DDKO mice ( $N=3-5 /$ group) and flash frozen in isopentane chilled in liquid nitrogen. These tissue samples were sectioned and stained with hematoxylin and eosin as previously described. ${ }^{56}$ Images were obtained using an Olympus BX61 microscope with DP71 camera (Center Valley, PA, USA).

For live myofiber imaging, mice were killed with $\mathrm{CO}_{2}$ asphyxiation and then muscles were dissected and intact FDB, biceps or EDL muscles were imaged directly as intact muscles or individual myofibers were isolated. For the latter, EDL muscle was placed in a sterile solution of collagenase type $1(2 \mathrm{mg} / \mathrm{ml}$ in Dulbecco's modified Eagle medium (DMEM) and incubated at $35^{\circ} \mathrm{C}$ shaking water bath for $1-2 \mathrm{~h}$. Individual muscle fibers were separated by gentle trituration with a fire-polished widemouthed Pasteur pipette. The individual fibers were washed three times with DMEM and placed in $35 \mathrm{~mm}$ glass bottom petri dishes that were precoated with matri-gel and supplied with growth medium (DMEM, 20\% FBS, 2\% chicken embryo extract, 1 : 100 dilution of Penicillin/streptomycin stock solution). The isolated fibers were maintained for $1-2$ days at $37^{\circ} \mathrm{C}$ and $5 \% \mathrm{CO}_{2}$ for further live imaging.

Prior to imaging, growth medium was removed and the myofibers were washed once with prewarmed cell imaging media (CIM; HBSS with $10 \mathrm{mM}$ HEPES pH 7.4 and $2 \mathrm{mM}$ $\mathrm{Ca}^{2+}$ ) at $37^{\circ} \mathrm{C}$ and then transferred to $\mathrm{CIM}$ containing $1.66 \mu \mathrm{g} / \mu \mathrm{l}$ of FM1-43 dye. Sarcolemma was injured by irradiating a $2-4 \mu \mathrm{m}^{2}$ area for $10 \mathrm{~ms}$ with the pulsed laser (Ablate, Intelligent Imaging Innovations, Inc., Denver, CO, USA). Repair kinetics was monitored by time-lapse imaging at $10 \mathrm{~s}$ intervals for 5 min using an inverted Olympus IX81 microscope (Olympus America, Center Valley, PA, USA) custom equipped with a CSUX1 spinning disc confocal unit (Yokogawa Electric Corp., Tokyo, Japan), pulsed laser Ablate, and diode laser of $561 \mathrm{~nm}$ (Cobolt, Stockholm, Sweden). Images were acquired using Evolve 512 EMCCD (Photometrics, Tucson, AZ, USA) at $1 \mathrm{~Hz}$. Image acquisition and laser injury was controlled using Slidebook 5.0 (Intelligent Imaging Innovations). The fibers that repaired were counted and presented as percentage. To monitor repair kinetics, the FM1-43 dye fluorescence in the myofiber was measured and plotted as change in intensity $\left(F / F_{0}\right.$; average $\left.\pm S . D\right)$ for each group.

Proteomic profiling and immunoblotting. Gastrocnemius mouse muscles were homogenized in radioimmunoprecipitation assay buffer (RIPA) buffer (50 mm Tris- $\mathrm{HCl}, \mathrm{pH} 8.0$, with $150 \mathrm{~mm}$ sodium chloride, 1.0\% Igepal CA-630 (Nonidet P-40), $0.5 \%$ sodium deoxycholate, and $0.1 \%$ sodium dodecyl sulfate) (Teknova, Hollister, CA, USA) containing protease inhibitors (Halt protease inhibitor mixture 100X; Thermo Fisher Scientific, Waltham, MA, USA). Protein concentrations were measured using the Thermo BCA Microplate Protein Assay (Thermo Fisher Scientific) according to the manufacturer's protocol. Approximately $50 \mu \mathrm{g}$ of each sample RIPA extract was mixed 1:1 with RIPA quadriceps protein extract from a 
SILAM mouse. ${ }^{28,29}$ The SILAM mouse is a mouse where all lysine residues have been replaced with ${ }^{13} \mathrm{C}_{6}$-lysine and serves as a SuperSILAC internal standard for quantitation. ${ }^{57}$ Samples underwent detergent removal (Thermo Fisher Scientific) and tryptic digestion using SmartDigest (Thermo Fisher Scientific) at $70{ }^{\circ} \mathrm{C}$ and 1400 r.p.m. for $1.5 \mathrm{~h}$. Resulting peptides were acidified to $0.1 \%$ TFA and fractioned into 8 fractions using high pH reverse-phase spin columns (Thermo no. 84868). Peptide fractions were dried by vacuum centrifugation and resuspended in $20 \mu \mathrm{l}$ of $0.1 \%$ formic acid and $2 \%$ acetonitrile. Each sample $(3 \mu \mathrm{l})$ was analyzed by top 15 data-dependent LC-MS/MS on a Thermo $Q$ Exactive HF mass spectrometer coupled online to a NanoEasy nano-LC 1000 with the following parameters: positive polarity, m/z 380-1600, MS Resolution 120000 , AGC 3e6, $50 \mathrm{~ms}$ IT, MS/MS Resolution 15000 , AGC 2e4, $100 \mathrm{~ms} \mathrm{IT}$, isolation width $1.4 \mathrm{~m} / \mathrm{z}$, and NCE 27 , underfill $5 \%$, unassigned and +1 ions excluded, peptide match preferred, isotope exclusion on, dynamic exclusion $30 \mathrm{~s}$, LC solvents A: $0.1 \%$ formic acid with $2 \%$ acetonitrile, B: $100 \%$ acetonitrile, precolumn: Thermo Acclaim Pepmap 100 $75 \mu \mathrm{m} \times 2 \mathrm{~cm} \mathrm{C18} 3 \mu \mathrm{m} 100 \mathrm{~A}$ (Thermo Fisher Scientific), analytical column: Thermo Pepmap RSLC C18 um 100 A $75 \mu \mathrm{m} \times 50 \mathrm{~cm}$, precolumn equilibration $4 \mu$ at $800 \mathrm{Bar}$, analytical column equilibration $6 \mu \mathrm{l}$ at $980 \mathrm{Bar}$, sample loading $6 \mu \mathrm{l}$ at 980 Bar, gradient $5-10 \%$ B in 2 min, to $25 \%$ B in 80 min, to $40 \%$ B in 8 min, to $90 \%$ $B$ in $5 \mathrm{~min}$ and held for $5 \mathrm{~min}$. Resulting mass spectral files were searched against the UniProt Mouse database using MaxQuant (http://www.coxdocs.org/doku.php? $\mathrm{id}=$ maxquant:start) with the following parameters: partially tryptic, 2 missed cleavages, heavy lysine 6.0201 Da, First Search 20 p.p.m. tolerance, Main Search 4.5 p.p.m. tolerance, PSM and Protein FDR 0.01. Resulting list of proteins were analyzed and visualized using the Perseus software (http://www.coxdocs.org/doku. php?id=perseus:start). Light/havy ratios were log2 transformed. Hierarchical clustering, Student's $t$-tests and group averages were calculated and visualized within Perseus.

For immunoblotting, protein lysates ( $25 \mu \mathrm{g}$ of protein) were resolved by electrophoresis, transferred onto a nitrocellulose membrane, and incubated overnight at $4^{\circ} \mathrm{C}$ with primary antibodies against dysferlin (1:1000; NCL-Hamlet, Leica biosystems, Newcastle Upon Tyne, UK), dystrophin (1:1000, Novocastra, San Jose, CA, USA), Annexin-1 (1: 2000, BD Biosciences, San Jose, CA, USA), Annexin-2 (1:2000, BD Biosciences), VDAC (1:1000, Abcam, Cambridge, MA, USA), LC3b (1:1000), or TOM20 (1:1000, Abcam). Polyclonal rabbit anti-mouse and goat antirabbit secondary antibodies (Dako, Carpinteria, CA, USA) conjugated to horseradish peroxidase $(1: 3000)$ were used as appropriate for $1 \mathrm{~h}$. The protein bands were revealed with ECL chemi-luminescence substrate (GE Healthcare, Pittsburgh, PA, USA). For quantification, the blots were exposed to X-ray films or scanned digitally with ChemiDoc Touch Imager. Densitometric analysis was carried out using a BioRad GS-800 calibrated densitometer and Quantity One software or Image Lab software (Bio-Rad, Hercules, CA, USA). Ratios of the optical density of each specific protein were normalized to the corresponding loading control.

Contraction-induced myofiber and sarcolemmal injury. After anesthetizing the mice with a mixture of ketamine and xylazine, EDL muscles from the right hind limb of C57BL/6, $m d x$, and DDKO mice were carefully exposed and 6-0 silk sutures were firmly attached to the proximal and distal tendons. The EDL was dissected and placed in a bath containing buffered mammalian Ringer's solution (137 mM NaCl, $24 \mathrm{mM} \mathrm{NaHCO}_{3}, 11 \mathrm{mM}$ glucose, $5 \mathrm{mM} \mathrm{KCl}, 2 \mathrm{mM} \mathrm{CaCl}$, $1 \mathrm{mM} \mathrm{MgSO}_{4}, 1 \mathrm{mM} \mathrm{NaH}_{2} \mathrm{PO}_{4}$ and $0.025 \mathrm{mM}$ tubocurarine chloride) at $25^{\circ} \mathrm{C}$ and bubbled with $95 \% \mathrm{O}_{2}-5 \% \mathrm{CO}_{2}$ to stabilize the $\mathrm{pH}$ at 7.4 . In the bath, the distal tendon was securely connected to a fixed bottom plate and the proximal tendon was attached to the arm of a servomotor ( $800 \mathrm{~A}$ in vitro muscle apparatus, Aurora Scientific, Aurora, ON, Canada). The vertically aligned EDL muscle was flanked by two stainless steel plate electrodes. Using single $0.2 \mathrm{~mm}$ square simulation pulses, the muscle was adjusted to the optimal muscle length for force generation. At optimal length, with isometric tetanic contractions $300 \mathrm{~ms}$ in duration at frequencies up to $250 \mathrm{~Hz}$ separated by 2 min of rest intervals, the maximal force was determined. Specific force, defined as maximal force normalized for the muscle cross sectional area, was calculated as the maximal force/(muscle mass $\times$ (density of muscle tissue $x$ fiber length) -1 ). The fiber length was based on the fiber-tomuscle length ratio of 0.45 . The muscle tissue density is $1.056 \mathrm{~kg} / \mathrm{l}$. The data were represented as mean \pm S.D. To study contraction-induced sarcolemmal injury, EDL muscles were subjected to 1,5 , or 9 LCs with $10 \%$ strain at a velocity of 2 fiber lengths per second. Each contraction was separated by a 1 min rest interval. LCinduced force deficits were expressed as the percentage of first contraction. The values were represented as mean \pm S.D.
After the protocol of LCs, muscles were pinned on cork at optimal length and placed in $0.2 \%$ PO dye Ringer-solution for $1 \mathrm{~h}$ at RT. After removing the excess dye by washing with Ringer's solution, the muscle was frozen using isopentane prechilled in liquid nitrogen. Frozen tissues were sectioned $(10 \mu \mathrm{m})$ and imaged under red channel using a Nikon Eclipse E800 (Nikon, Sendai, Japan) microscope that was fitted with a SPOT digital color camera with SPOT advanced software (Diagnostic Instruments, Sterling Heights, MI, USA). Representative pictures (×20) were taken and PO-positive fibers/image was quantified for each section. Data are represented as the number of PO-positive fibers per image (mean \pm S.D.).

Measurement of inflammation marker. IL-1 $\beta$ inflammatory marker was monitored using real-time quantitative PCR assay as previously described. ${ }^{29}$ In brief, quadriceps muscle tissue was obtained from 28-day-old C57BL/6, mdx-52, and DDKO mice. RNA was isolated using TRlzol according to the protocol recommended by the manufacturer (Life Technologies, Carlsbad, CA, USA). Complementary DNA was synthesized using a High Capacity CDNA Reverse Transcription Kit with RNase Inhibitor (Life Technologies). Quantitative PCR was performed using an Applied Biosystems 7900HT Real-Time PCR machine. TaqMan probe sets IL-1b (Mm00434228_m1) and hypoxanthine guanine phosphoribosyl transferase (HPRT; Mm01545399_m1) were obtained from Applied Biosystems (Foster City, CA, USA). The relative expression of the transcript was calculated according to the $\Delta \Delta \mathrm{Ct}$ method with HPRT as the internal reference, and fold change is expressed as the mean \pm S.D.

Monitoring the mitochondrial dynamics and activity. For monitoring in situ mitochondrial dynamics, isolated or intact myofibers and cultured $\mathrm{C}_{2} \mathrm{C} 12$ myoblasts were stained for $15 \mathrm{~min}$ at $37^{\circ} \mathrm{C}$ with $100 \mathrm{nM}$ MitoTracker Orange CM-H2TMRos (Thermo Fisher Scientific). The excess dye was washed off, and the fibers were transferred to CIM. Myofibers were injured using a pulsed laser and imaged as described above. In cell culture experiments, $\mathrm{C} 2 \mathrm{C} 12$ myoblasts were incubated in $100 \mathrm{mM}$ pyruvate for $10 \mathrm{~min}$ or $5 \mu \mathrm{M} \mathrm{CCCP}$ for $45 \mathrm{~min}$ at $37^{\circ} \mathrm{C}$ prior to labeling, and following washes, the cells were transferred to CIM containing the indicated drug for imaging. The fluorescence intensity of MitoTracker dye at the site of injury or in the whole cell (as indicated) was measured and the data are presented as means \pm S.D.

To assess mitochondrial respiratory activity, muscle tissues (gastrocnemius) were harvested and homogenized in ice-cold $\mathrm{H}$ medium (70 mM sucrose, $220 \mathrm{mM}$ mannitol, $2.5 \mathrm{mM}$ 4-(2-hydroxyethyl)-1-piperazineethanesulfonic acid, $\mathrm{pH} 7.4$, and $2 \mathrm{mM}$ EDTA). The homogenate was centrifuged at $1500 \times \mathrm{g}$ for $10 \mathrm{~min}$ at $4^{\circ} \mathrm{C}$. Supernatants were removed and centrifuged at $10000 \times g$ for $10 \mathrm{~min}$ at $4^{\circ} \mathrm{C}$. The mitochondria pellets were resuspended in $\mathrm{H}$ medium and centrifuged at $10000 \times g$ for 10 min at $4^{\circ} \mathrm{C}$. Pellets were again resuspended in $\mathrm{H}$ medium, and mitochondrial protein concentration was determined by the Protein Assay Kit (Bio-Rad).

Cytochrome oxidase kinetics was determined spectrophotometrically, using the method of Smith, in which the rate of oxidation of ferrocytochrome $c$ was measured by following the decrease in absorbance at $550 \mathrm{~nm}$. An average of $1.5 \mu \mathrm{g}$ of mitochondria was resuspended in reaction buffer (1 M phosphate buffer, $2 \%$ dodecyl maltoside) and the reaction was started by addition of reduced ferocytochrome $c$ at 2-80 $\mu \mathrm{M}$. Specific activity was calculated as the average of four measurements using $21.1 / \mathrm{mM} / \mathrm{cm}$ as the extinction coefficient of ferrocytochrome $c$ at $550 \mathrm{~nm}^{58}$

Live cell ATP Imaging. To measure mitochondrial ATP, C2C12 myoblasts were transfected with the FRET-based ATP biosensor ATeam. ${ }^{46}$ Cells were first imaged in $\mathrm{CIM}$ (untreated) and then allowed to incubate in $100 \mathrm{mM}$ pyruvate for $10 \mathrm{~min}$ at $37^{\circ} \mathrm{C}$. After incubation, same cells were imaged to determine the change in ATeam FRET emission for each cell. Three-channel FRET imaging was performed by monitoring the donor (445 laser excitation), acceptor (515 laser excitation), and transfer (FRET) channels. Emission from these three channels was corrected for bleed through and used to measure corrected FRET: $\mathrm{FC}=$ Transfer-Acceptor-Donor, which generated a corrected FRET image and the FRET quantification.

Antisense oligonucleotide and pyruvate treatment. As previously described, mice were anesthetized using $4 \%$ isoflurane and $0.5 \mathrm{l} / \mathrm{min} \mathrm{100 \%} \mathrm{oxygen}$ and maintained using $2 \%$ isoflurane and $0.5 \mathrm{l} / \mathrm{min}$ oxygen delivered via a nose cone with a passive exhaust system on a warming device. ${ }^{59}$ The $A O$ of choice was the morpholino chemistry, PMO mExon 23(+07-18) (5'-GGCCAAACCTCGGCTTA CCTGAAAT- $3^{\prime}$ ) against the boundary sequences of exon and intron 23 of the mouse dystrophin gene (Gene Tools, Philomath, OR, USA). PMO was either 
administered via a single $800 \mathrm{mg} / \mathrm{kg}$ dose through an IV injection via the retroorbital sinus as previously described ${ }^{44}$ or through weekly IM injections to the FDB muscle for 3 weeks (20 mg PMO/dose). After each injection, the mouse was monitored for pain or distress. Age-matched control $m d x$ mice were left untreated. Uninjected C57BL/10 mice were used as dystrophin-positive controls.

For pyruvate treatment, biceps muscle from $m d x-23$ mice were dissected and incubated with pyruvate (100 mM salt, Sigma, St. Louis, MO, USA) for $25 \mathrm{~min}$ at $37^{\circ} \mathrm{C}$ before laser injury in the presence of FM1-43 dye (as described earlier). The same procedure was carried out for FDB muscles and mitochondria potential measured using MitoTracker Red (CM-H2TMRos) as above. Contralateral muscles were used as untreated controls.

Statistical analyses. Statistical analyses were performed using either Student's $t$-test or one-way analysis of variance (with Bonferroni correction posttest) where appropriate. When data are not normally distributed, non-parametric Mann-Whitney test was used to determine the statistical significance. Calculations were performed with GraphPad Prism version 6 (Graphpad Software, Inc., La Jolla, CA, USA) and $P<0.05$ was considered significant.

\section{Conflict of Interest}

The authors declare no conflict of interest.

Acknowledgements. SR and MCV performed these studies as part of their doctoral studies at the Institute for Biomedical Sciences at the George Washington University and the work here from part of their $\mathrm{PhD}$ dissertations. We thank Dr. Isabelle Richard (Genethon, France) for the gift of B6A/J mouse model. Financial support was provided by NIAMS (R01AR055686) and MDA (MDA277389) to JKJ as well as by NIH (K26OD011171; R24HD050846, P50AR060836, U54HD071601) and the US Department of Defense (W81XWH-05-1-0659, W81XWH-11-1-0782, W81XWH-11-1-0330) grants to KN. The microscopy core is supported by NIH core grant IDDRC P30HD040677.

\section{Author contributions}

MCV and SR conducted the work described here with help from MH in the therapeutic and histological analysis, from JVM in muscle physiology studies, from $A D$ in live myofiber imaging, from $\mathrm{AH}$ in live myofiber and live cell studies and from $\mathrm{KJB}$ and $\mathrm{YH}$ in proteomic studies. ST contributed new reagents; $\mathrm{KN}$ and JKJ conceived this study and provided oversight. JKJ designed the experimental approaches with help from all authors and participated in data collection, analysis and interpretation. MCV and JKJ wrote the manuscript with help from all the authors.

1. Hoffman EP, Kunkel LM. Dystrophin abnormalities in Duchenne/Becker muscular dystrophy. Neuron 1989; 2: 1019-1029.

2. Ervasti JM, Campbell KP. A role for the dystrophin-glycoprotein complex as a transmembrane linker between laminin and actin. J Cell Biol 1993; 122: 809-823.

3. Wallace GQ, McNally EM. Mechanisms of muscle degeneration, regeneration, and repair in the muscular dystrophies. Annu Rev Physiol 2009; 71: 37-57.

4. Petrof BJ, Shrager JB, Stedman HH, Kelly AM, Sweeney HL. Dystrophin protects the sarcolemma from stresses developed during muscle contraction. Proc Natl Acad Sci USA 1993; 90: 3710-3714.

5. Pasternak C, Wong S, Elson EL. Mechanical function of dystrophin in muscle cells. J Cell Biol 1995; 128: 355-361.

6. Menke A, Jockusch H. Decreased osmotic stability of dystrophin-less muscle cells from the mdx mouse. Nature 1991; 349: 69-71.

7. Lynch GS, Rafael JA, Chamberlain JS, Faulkner JA. Contraction-induced injury to single permeabilized muscle fibers from mdx, transgenic mdx, and control mice. Am J Physiol Cell Physiol 2000; 279: C1290-C1294.

8. Franco A Jr, Lansman JB. Calcium entry through stretch-inactivated ion channels in $\mathrm{mdx}$ myotubes. Nature 1990; 344: 670-673.

9. McCarter GC, Steinhardt RA. Increased activity of calcium leak channels caused by proteolysis near sarcolemmal ruptures. J Membr Biol 2000; 176: 169-174.

10. Turner PR, Westwood T, Regen CM, Steinhardt RA. Increased protein degradation results from elevated free calcium levels found in muscle from mdx mice. Nature 1988; 335: 735-738.

11. Peault B, Rudnicki M, Torrente Y, Cossu G, Tremblay JP, Partridge T et al. Stem and progenitor cells in skeletal muscle development, maintenance, and therapy. Mol Ther 2007; 15: 867-877.

12. Han R, Rader EP, Levy JR, Bansal D, Campbell KP. Dystrophin deficiency exacerbates skeletal muscle pathology in dysferlin-null mice. Skelet Muscle 2011; 1: 35
13. Vontzalidis A, Terzis $G$, Manta $P$. Increased dysferlin expression in Duchenne muscular dystrophy. Anal Quant Cytopathol Histpathol 2014; 36: 15-22.

14. Heier CR, Damsker JM, Yu Q, Dillingham BC, Huynh T, Van der Meulen JH et al. VBP15, a novel anti-inflammatory and membrane-stabilizer, improves muscular dystrophy without side effects. EMBO Mol Med 2013; 5: 1569-1585.

15. Spurney CF, Guerron AD, Yu Q, Sali A, van der Meulen JH, Hoffman EP et al. Membrane sealant Poloxamer P188 protects against isoproterenol induced cardiomyopathy in dystrophin deficient mice. BMC Cardiovasc Disord 2011; 11: 20.

16. Townsend D, Turner I, Yasuda S, Martindale J, Davis J, Shillingford M et al. Chronic administration of membrane sealant prevents severe cardiac injury and ventricular dilatation in dystrophic dogs. J Clin Invest 2010; 120: 1140-1150.

17. Yasuda S, Townsend D, Michele DE, Favre EG, Day SM, Metzger JM. Dystrophic heart failure blocked by membrane sealant poloxamer. Nature 2005; 436: 1025-1029.

18. Fong PY, Turner PR, Denetclaw WF, Steinhardt RA. Increased activity of calcium leak channels in myotubes of Duchenne human and mdx mouse origin. Science 1990; 250: 673-676.

19. $\mathrm{Ng} \mathrm{R}$, Metzger JM, Claflin DR, Faulkner JA. Poloxamer 188 reduces the contraction-induced force decline in lumbrical muscles from mdx mice. Am J Physiol Cell Physiol 2008; 295: C146-C150.

20. Yeung EW, Whitehead NP, Suchyna TM, Gottlieb PA, Sachs F, Allen DG. Effects of stretchactivated channel blockers on [Ca2+]i and muscle damage in the mdx mouse. $J$ Physio 2005; 562: 367-380.

21. Shkryl VM, Martins AS, Ullrich ND, Nowycky MC, Niggli E, Shirokova N. Reciprocal amplification of $\mathrm{ROS}$ and $\mathrm{Ca}(2+)$ signals in stressed $\mathrm{mdx}$ dystrophic skeletal muscle fibers. Pflugers Arch 2009; 458: 915-928.

22. Robert V, Massimino ML, Tosello V, Marsault R, Cantini M, Sorrentino V et al. Alteration in calcium handling at the subcellular level in mdx myotubes. J Biol Chem 2001; 276: 4647-4651.

23. Millay DP, Goonasekera SA, Sargent MA, Maillet M, Aronow BJ, Molkentin JD. Calcium influx is sufficient to induce muscular dystrophy through a TRPC-dependent mechanism. Proc Natl Acad Sci USA 2009; 106: 19023-19028.

24. Leijendekker WJ, Passaquin AC, Metzinger L, Ruegg UT. Regulation of cytosolic calcium in skeletal muscle cells of the mdx mouse under conditions of stress. Br J Pharmacol 1996; 118: 611-616.

25. Goonasekera SA, Davis J, Kwong JQ, Accornero F, Wei-LaPierre L, Sargent MA et al. Enhanced $\mathrm{Ca}(2)(+)$ influx from STIM1-Orai1 induces muscle pathology in mouse models of muscular dystrophy. Hum Mol Genet 2014; 23: 3706-3715.

26. Iwata Y, Katanosaka Y, Arai Y, Shigekawa M, Wakabayashi S. Dominant-negative inhibition of $\mathrm{Ca} 2+$ influx via TRPV2 ameliorates muscular dystrophy in animal models. Hum Mol Genet 2009; 18: 824-834.

27. Vandebrouck C, Martin D, Colson-Van Schoor M, Debaix H, Gailly P. Involvement of TRPC in the abnormal calcium influx observed in dystrophic (mdx) mouse skeletal muscle fibers. J Cell Biol 2002; 158: 1089-1096.

28. Sharma N, Medikayala S, Defour A, Rayavarapu S, Brown KJ, Hathout $Y$ et al. Use of quantitative membrane proteomics identifies a novel role of mitochondria in healing injured muscles. J Biol Chem 2012; 287: 30455-30467.

29. Rayavarapu S, Coley W, Cakir E, Jahnke V, Takeda S, Aoki Y et al. Identification of disease specific pathways using in vivo SILAC proteomics in dystrophin deficient mdx mouse. Mol Cell Proteomics 2013; 12: 1061-1073.

30. Shibuya $S$, Wakayama $Y$. Changes in muscle plasma membranes in young mice with X chromosome-linked muscular dystrophy: a freeze-fracture study. Neuropathol Appl Neurobiol 1991; 17: 335-344.

31. McArdle A, Edwards RH, Jackson MJ. Time course of changes in plasma membrane permeability in the dystrophin-deficient mdx mouse. Muscle Nerve 1994; 17: 1378-1384.

32. Araki E, Nakamura K, Nakao K, Kameya S, Kobayashi O, Nonaka I et al. Targeted disruption of exon 52 in the mouse dystrophin gene induced muscle degeneration similar to that observed in Duchenne muscular dystrophy. Biochem Biophys Res Commun 1997; 238 . 492-497.

33. Defour A, Sreetama SC, Jaiswal JK. Imaging cell membrane injury and subcellular processes involved in repair. J Vis Exp 2014; 85: e51106.

34. Bansal D, Campbell KP. Dysferlin and the plasma membrane repair in muscular dystrophy. Trends Cell Biol 2004; 14: 206-213.

35. Kuznetsov AV, Winkler K, Wiedemann FR, von Bossanyi P, Dietzmann K, Kunz WS Impaired mitochondrial oxidative phosphorylation in skeletal muscle of the dystrophindeficient mdx mouse. Mol Cell Biochem 1998; 183: 87-96.

36. Sperl W, Skladal D, Gnaiger E, Wyss M, Mayr U, Hager J et al. High resolution respirometry of permeabilized skeletal muscle fibers in the diagnosis of neuromuscular disorders. $\mathrm{Mol} \mathrm{Cell}$ Biochem 1997; 174: 71-78.

37. Pendergrass W, Wolf N, Poot M. Efficacy of MitoTracker Green and CMXrosamine to measure changes in mitochondrial membrane potentials in living cells and tissues. Cytometry A 2004; 61: 162-169.

38. Chen H, Detmer SA, Ewald AJ, Griffin EE, Fraser SE, Chan DC. Mitofusins Mfn1 and Mfn2 coordinately regulate mitochondrial fusion and are essential for embryonic development. J Cell Biol 2003; 160: 189-200.

39. Fiacco E, Castagnetti F, Bianconi V, Madaro L, De Bardi M, Nazio F et al. Autophagy regulates satellite cell ability to regenerate normal and dystrophic muscles. Cell Death Differ 2016; 23: 1839-1849. 
40. Defour A, Van der Meulen JH, Bhat R, Bigot A, Bashir R, Nagaraju K et al. Dysferlin regulates cell membrane repair by facilitating injury-triggered acid sphingomyelinase secretion. Cell Death Dis 2014; 5: e1306.

41. Scheffer LL, Sreetama SC, Sharma N, Medikayala S, Brown KJ, Defour A et al. Mechanism of $\mathrm{Ca}(2)(+)$-triggered ESCRT assembly and regulation of cell membrane repair. Nat Commun 2014; 5 : 5646.

42. Hornsey MA, Laval SH, Barresi R, Lochmuller H, Bushby K. Muscular dystrophy in dysferlindeficient mouse models. Neuromuscul Disord 2013; 23: 377-387.

43. Lostal W, Bartoli M, Bourg N, Roudaut C, Bentaib A, Miyake K et al. Efficient recovery of dysferlin deficiency by dual adeno-associated vector-mediated gene transfer. Hum $\mathrm{Mol}$ Genet 2010; 19: 1897-1907.

44. Vila MC, Klimek MB, Novak JS, Rayavarapu S, Uaesoontrachoon K, Boehler JF et al. Elusive sources of variability of dystrophin rescue by exon skipping. Skelet Muscle 2015; 5: 44.

45. Pant M, Sopariwala DH, Bal NC, Lowe J, Delfin DA, Rafael-Fortney J et al. Metabolic dysfunction and altered mitochondrial dynamics in the utrophin-dystrophin deficient mouse model of duchenne muscular dystrophy. PLOS One 2015; 10: e0123875.

46. Imamura H, Nhat KP, Togawa H, Saito K, lino R, Kato-Yamada $Y$ et al. Visualization of ATP levels inside single living cells with fluorescence resonance energy transfer-based genetically encoded indicators. Proc Natl Acad Sci USA 2009; 106: 15651-15656.

47. Jahnke VE, Van Der Meulen JH, Johnston HK, Ghimbovschi S, Partridge T, Hoffman EP et al. Metabolic remodeling agents show beneficial effects in the dystrophin-deficient $\mathrm{mdx}$ mouse model. Skelet Muscle 2012; 2: 16-16.

48. Selsby JT, Morine KJ, Pendrak K, Barton ER, Sweeney HL. Rescue of dystrophic skeletal muscle by PGC-1alpha involves a fast to slow fiber type shift in the $\mathrm{mdx}$ mouse. PLoS One 2012; 7: e30063.

49. Chan MC, Rowe GC, Raghuram S, Patten IS, Farrell C, Arany Z. Post-natal induction of PGC-1alpha protects against severe muscle dystrophy independently of utrophin. Skelet Muscle 2014; 4: 2

50. Ljubicic V, Miura P, Burt M, Boudreault L, Khogali S, Lunde JA et al. Chronic AMPK activation evokes the slow, oxidative myogenic program and triggers beneficial adaptations in mdx mouse skeletal muscle. Hum Mol Genet 2011; 20: 3478-3493.

51. Godin R, Daussin F, Matecki S, Li T, Petrof BJ, Burelle Y. Peroxisome proliferator-activated receptor gamma coactivator1- gene alpha transfer restores mitochondrial biomass and improves mitochondrial calcium handling in post-necrotic mdx mouse skeletal muscle. J Physiol 2012; 590: 5487-5502.

52. Hosur V, Kavirayani A, Riefler J, Carney LM, Lyons B, Gott B et al. Dystrophin and dysferlin double mutant mice: a novel model for rhabdomyosarcoma. Cancer Genet 2012; 205: 232-241.
53. Waddell LB, Lemckert FA, Zheng XF, Tran J, Evesson FJ, Hawkes JM et al. Dysferlin, annexin $A 1$, and mitsugumin 53 are upregulated in muscular dystrophy and localize to longitudinal tubules of the T-system with stretch. J Neuropathol Exp Neurol 2011; 70: 302-313.

54. Godfrey C, Muses S, McClorey G, Wells KE, Coursindel T, Terry RL et al. How much dystrophin is enough: the physiological consequences of different levels of dystrophin in the mdx mouse. Hum Mol Genet 2015; 24: 4225-4237.

55. van den Bergen JC, Wokke BH, Janson AA, van Duinen SG, Hulsker MA, Ginjaar HB et al. Dystrophin levels and clinical severity in Becker muscular dystrophy patients. $J$ Neurol Neurosurg Psychiatry 2014; 85: 747-753.

56. Spurney CF, Gordish-Dressman H, Guerron AD, Sali A, Pandey GS, Rawat R et al. Preclinical drug trials in the $\mathrm{mdx}$ mouse: assessment of reliable and sensitive outcome measures. Muscle Nerve 2009; 39: 591-602.

57. Geiger T, Wisniewski JR, Cox J, Zanivan S, Kruger M, Ishihama Y et al. Use of stable isotope labeling by amino acids in cell culture as a spike-in standard in quantitative proteomics. Nat Protoc 2011; 6: 147-157.

58. Piel DA, Deutschman CS, Levy RJ. Exogenous cytochrome C restores myocardial cytochrome oxidase activity into the late phase of sepsis. Shock 2008; 29: 612-616.

59. Baudy AR, Sali A, Jordan S, Kesari A, Johnston HK, Hoffman EP et al. Non-invasive optical imaging of muscle pathology in $\mathrm{mdx}$ mice using cathepsin caged near-infrared imaging. Mol Imaging Biol 2011; 13: 462-470.

(c) (i) (2) This work is licensed under a Creative Commons Attribution-NonCommercial-ShareAlike 4.0 International License. The images or other third party material in this article are included in the article's Creative Commons license, unless indicated otherwise in the credit line; if the material is not included under the Creative Commons license, users will need to obtain permission from the license holder to reproduce the material. To view a copy of this license, visit http://creativecommons.org/licenses/by-nc-sa/4.0/

(C) The Author(s) 2017

Supplementary Information accompanies this paper on Cell Death and Differentiation website (http://www.nature.com/cdd) 